
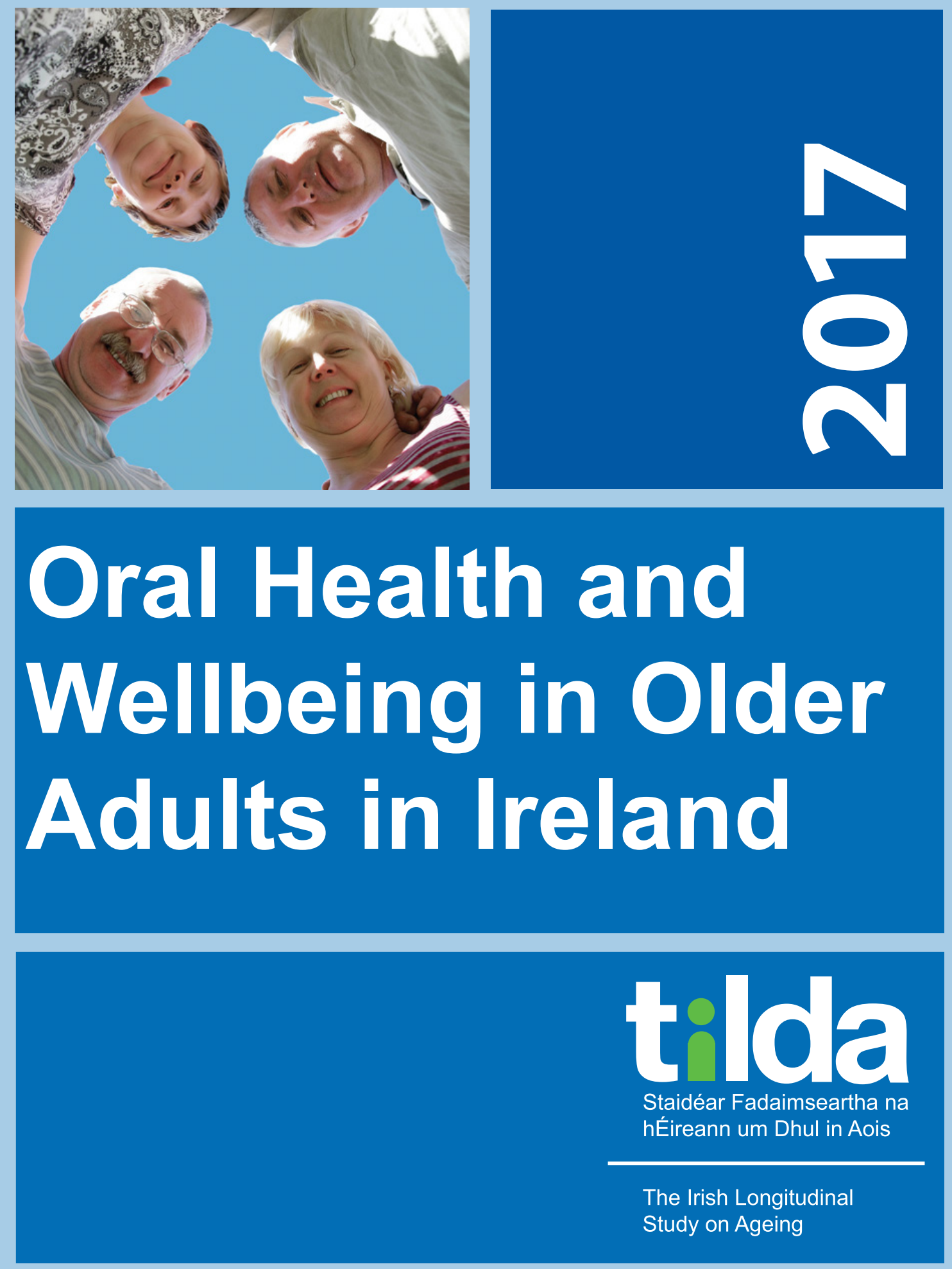


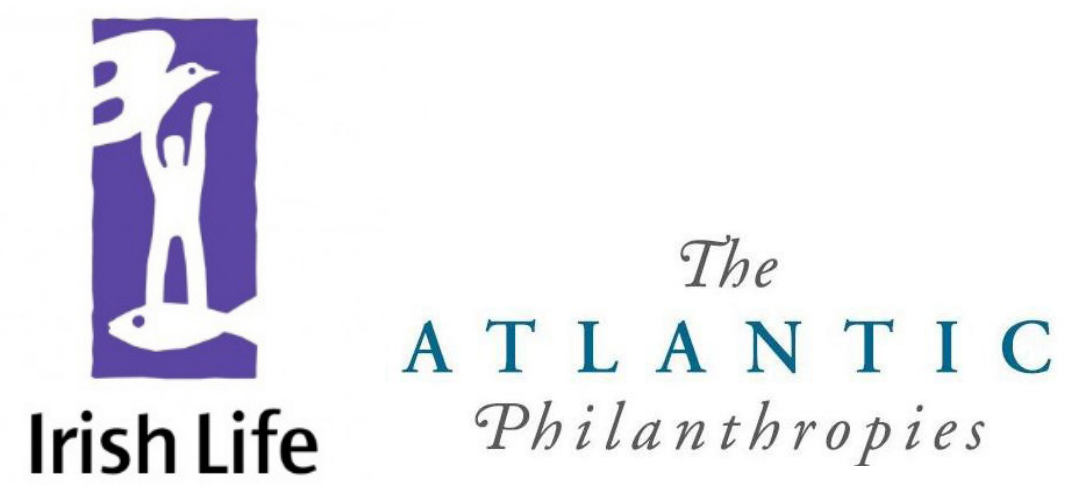




\section{Oral Health and Wellbeing in Older Irish Adults}

Aideen Sheehan, Christine McGarrigle, Brian O'Connell

On behalf of the TILDA team

October 2017 
Copyright (@) The Irish Longitudinal Study on Ageing 2017

The Irish Longitudinal Study on Ageing

Lincoln Place

Trinity College Dublin

Dublin 2

Tel: +35318962509

Email: tilda@tcd.ie

Website: www.tilda.ie

https://www.doi.org/10.38018/TildaRe.2017-04 


\section{Key Findings}

- One in six (18\%) of adults aged 54 years and over in Ireland has no natural teeth although most have dentures in place of teeth.

- Prevalence of tooth loss increases with age, with $40 \%$ of those aged 75 years and over having no natural teeth compared to $7 \%$ of those aged 54 to 64 years.

- Older adults living in rural Ireland are twice as likely to have lost all their teeth as those resident in Dublin (22\% versus $10 \%$ ).

- Rural dwellers also visit their dentist less frequently, with $15 \%$ not attending at all in recent years compared to $7 \%$ in Dublin.

- Older adults who have lost their teeth are more likely to be current smokers, than those who have retained them and the difference is particularly noted in those aged 54 to 64 years (40\% versus $15 \%)$.

- Overall, $6 \%$ of older adults report problems with everyday activities such as eating, speaking or laughing because of issues with their mouth/teeth or dentures, while over a quarter of those with no teeth, with or without dentures experience difficulties with activities such as eating, smiling or speaking.

- Older adults with no teeth, with or without dentures report less active social participation, lower quality of life, increased depressive symptoms, and increased loneliness compared to adults with all their own teeth.

- Use and awareness of state dental services is low, particularly amongst those with no teeth. 


\section{Acknowledgements}

We would like to acknowledge the vision and commitment of our funders, Irish Life, The Atlantic Philanthropies and the Department of Health, which is providing funding on behalf of the state. We would also like to state that any views expressed in this report are not necessarily those of the Department of Health or of the Minister of Health. We would also like to thank the TILDA participants without whom this research would not be possible. 


\section{Contents}

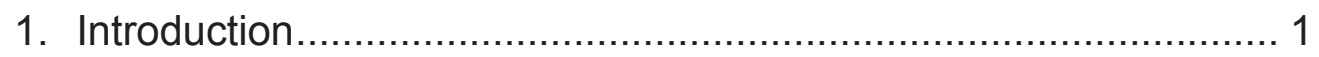

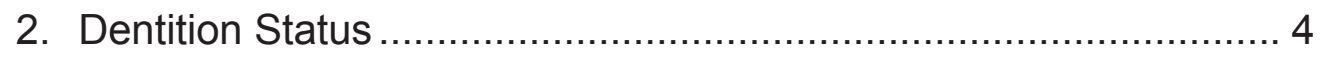

3. Dental healthcare utilisation ............................................. 10

4. Dentition Status and Physical Health ............................... 16

5. Dentition Status and Wellbeing .......................................... 22

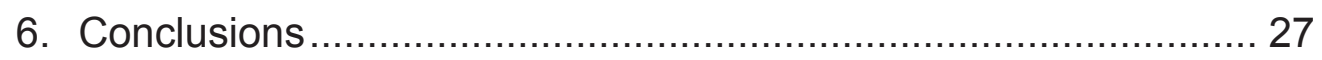

7. References .................................................................... 30

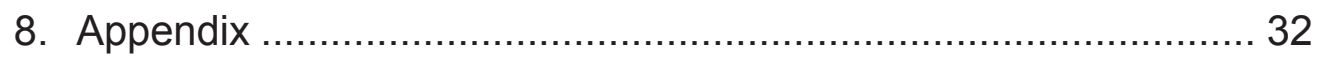




\section{Introduction}

Research has shown that poor oral health and loss of teeth are associated with lower quality of life in older people as measured by psychological wellbeing, life satisfaction (1) and functional and emotional wellbeing (2, 3, 4). This association persists even after controlling for other factors that may also account for lower quality of life. Loss of all teeth is associated with reduced social participation of older adults and is associated with poorer quality of life, particularly amongst women and those with no formal education (5).

In Ireland, oral health status has been found to be associated with quality of life and adults with better oral health associated with increased quality of life. However, adults aged 65 and over and medical cardholders had the poorest oral health related quality of life (6). The most common negative effects reported were in relation to appearance, smiling/laughing, breath odour and finances. Not surprisingly, oral health has significance beyond the mouth: periodontal disease and diabetes are believed to have a bi-directional relationship (7). Additionally, research has indicated an association between periodontitis and ischemic stroke (8) and between the number of teeth and coronary heart disease (9), indicating the importance of good dental health to other health outcomes in addition to wellbeing.

Tooth loss and rates of edentulism (the loss of all teeth) are an important marker of dental health. The World Health Organisation has shown that worldwide edentulism rates among $65-74$-year-olds vary from $10 \%$ in low-income countries to $35 \%$ in upper-middle income countries - partly due to a past tendency in some high-income countries to extract all teeth early in life to reduce pain or discomfort. Within countries there is considerable social inequality, with tooth loss more prevalent amongst those with less educational attainment and lower income $(10,11)$. Tooth loss in older adults can be the result of many other causes in addition to caries, such as trauma, periodontal disease, tooth wear and access to dental care. Previous TILDA research found that respondents having their own teeth was associated with the likelihood of water supplies being fluoridated in their area (12).

In Ireland, edentulism rates have fallen dramatically in recent decades from $72 \%$ of adults aged 65 and over in 1979 to $41 \%$ in 2002, with women and medical cardholders more likely to have no teeth (6). The number of people aged 65 years and over with dentures 
rose to $74 \%$ in that time period, mainly due to a sharp increase to $43 \%$ in the numbers wearing partial dentures. The number of edentulous adults aged 35 to 44 years fell to under $1 \%$ in 2002.

\section{Aim}

This report examines the self-reported oral health of older adults in Ireland as measured by their dentition status, use of dental healthcare and reports of oral-health related problems. Whether oral health is associated with social participation, mental health and wellbeing is also explored.

\section{Data and Methodology}

This report uses data collected during the third wave of The Irish Longitudinal Study on Ageing (TILDA), a prospective study of 8,175 adults aged 50 years and older, representative of the community-dwelling middle-aged and older Irish population. Data for Wave 3 was collected between March 2014 and October 2015. Respondents were interviewed in their own homes using a Computer Assisted Personal Interview (CAPI). This included detailed questions on socio-demographics, living circumstances, income and wealth, physical, mental and behavioural health, health care utilisation, social support and social participation. Participants were also asked to fill out a self-completion questionnaire (SCQ) which included more sensitive questions about relationships and experiences of getting older, which they returned via a pre-stamped addressed envelope. This report uses a sample of 6,425 adults aged 54 years and over who undertook a CAPI-interview in Wave 3 of TILDA. As questions about social participation and quality of life are answered in the SCQ, the current analysis includes respondents who completed and returned the SCQ $(5,653)$.

In this report, we present the percentage of participants classified into different groups or average scores (means) on the different outcome scales. Most estimates are provided with a $95 \%$ confidence interval which can be interpreted as a $95 \%$ chance that the sampled confidence interval includes the true population value. All estimates are weighted to account for age, sex and educational attainment in the 2011 Census ensuring that these estimates are representative of the whole population aged over 50 in Ireland.

\section{Report Structure}

Chapter 2 investigates the self-reported oral health status of older adults in Ireland by socio-demographic characteristics and by physical and behavioural health indicators. 
Chapter 3 then examines type and frequency of dental care used and reported problems encountered because of oral health issues. Chapter 4 examines the association between oral health status and quality of life, as measured by quality of life indicators, mental health outcomes, active social participation and loneliness scales. Finally, Chapter 5 summarises the findings and discusses implications for policy. 


\section{Dentition Status}

Participants were asked which of the following five categories best describes the teeth they have - (1) all their own natural teeth, (2) their own teeth but some missing; (3) dentures and some of their own teeth; (4) full dentures or (5) no teeth or dentures. As shown in Table 1, 8\% have retained all their own teeth, while 38\% have only their own teeth but are missing some. A further $37 \%$ have a mix of dentures and their own teeth, while $17 \%$ have full dentures and $1 \%$ have neither teeth nor dentures. For the purpose of analysis participants were regrouped into three categories - those with their own teeth and no dentures $(45 \%)$; those with a mix of dentures and their own teeth (38\%) and those with no teeth with or without dentures $(17 \%)$.

Table 1. Self-assessment of teeth in the TILDA sample aged 54 years and over, and weighted percentages for the Irish population

\begin{tabular}{|c|c|c|c|}
\hline $\begin{array}{c}\text { Which best describes the } \\
\text { teeth you have? }\end{array}$ & Frequency & $\begin{array}{c}\text { Sample } \\
\text { Percentage }\end{array}$ & $\begin{array}{c}\text { Population percentage } \\
\text { (weighted) }\end{array}$ \\
\hline Own teeth, no dentures & $\mathbf{2 , 9 0 3}$ & $\mathbf{4 5 . 3}$ & $\mathbf{4 5 . 1}$ \\
\hline All own teeth & 467 & 7.3 & 7.5 \\
\hline Own teeth, some missing & 2,436 & 38.0 & 37.7 \\
\hline Mix of dentures and own teeth & $\mathbf{2 , 3 9 8}$ & $\mathbf{3 7 . 4}$ & $\mathbf{3 6 . 9}$ \\
\hline No teeth +/- dentures & $\mathbf{1 , 1 1 4}$ & $\mathbf{1 7 . 4}$ & $\mathbf{1 8 . 0}$ \\
\hline Full dentures & 1,056 & 16.5 & 17.0 \\
\hline No teeth or dentures & 58 & 0.9 & 1.0 \\
\hline
\end{tabular}

$\mathrm{n}=6,425,10$ missing values 


\section{Demographic characteristics by dentition status}

Older participants and women are more likely to have lost all their teeth. Just $7 \%$ of people aged 54 to 64 years have lost all their teeth compared to $41 \%$ of those aged 75 years and over. Figure 1 shows that while a similar trend of more prevalent tooth loss with age is seen for both men and women, overall women are more likely to have lost all their own teeth ( $21 \%$ versus $15 \%$ of men) and less likely to have retained them ( $41 \%$ versus $50 \%$ of men).

Figure 1. Self-assessed dentition status by age and sex

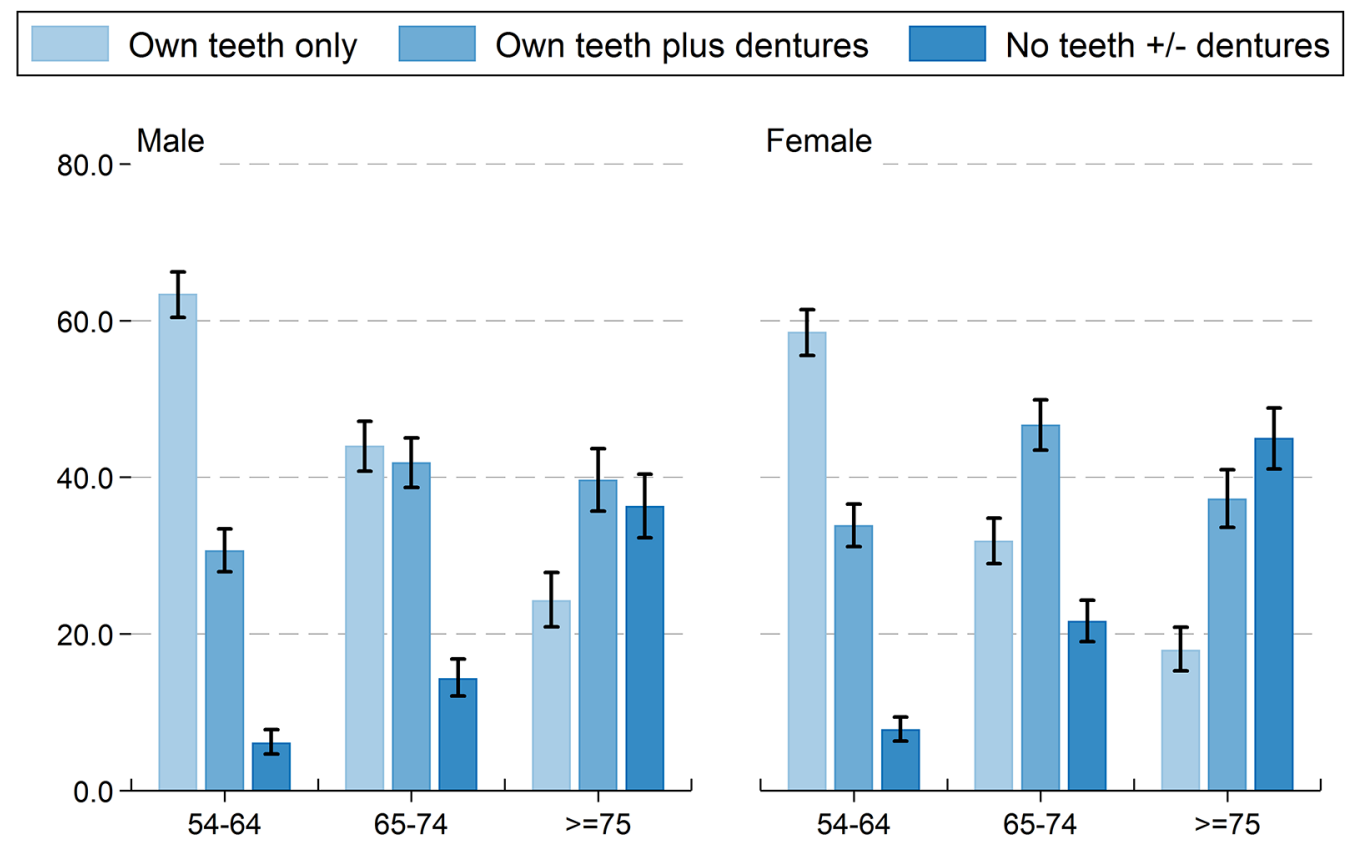

Note. $\mathrm{N}=6415$; Missing obs = 10; Error bars correspond to $95 \%$ confidence intervals 
Figure 2 shows that retention and loss of teeth varies by educational attainment. Older adults who have retained their own teeth have higher educational attainment than those who have not, with $29 \%$ achieving a third-level education compared to $8 \%$ of those with no teeth. Just $24 \%$ of those with their own teeth have only primary education compared with $59 \%$ of those with no teeth. Similar trends were seen for both men and women, and across all age groups.

Figure 2. Self-assessed dentition status by education and age

\begin{tabular}{|l|l|}
\hline Own teeth only $\square$ Own teeth plus dentures $\square$ No teeth $+/$ - dentures \\
$\square$
\end{tabular}

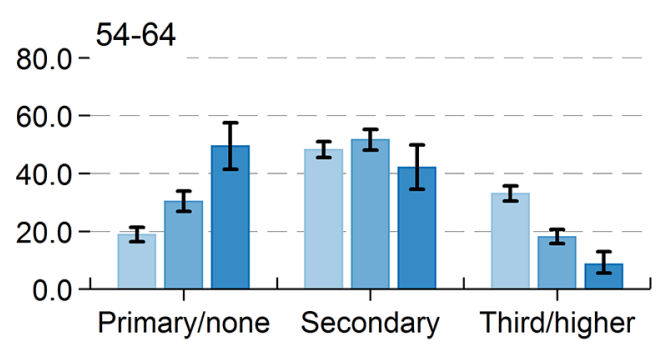

$65-74$

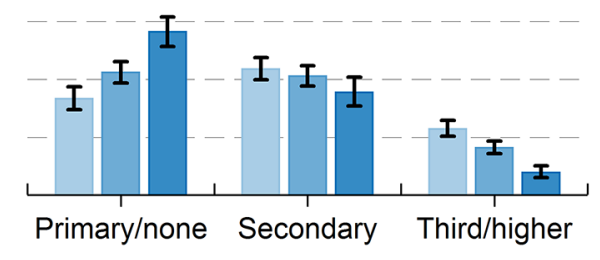

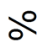

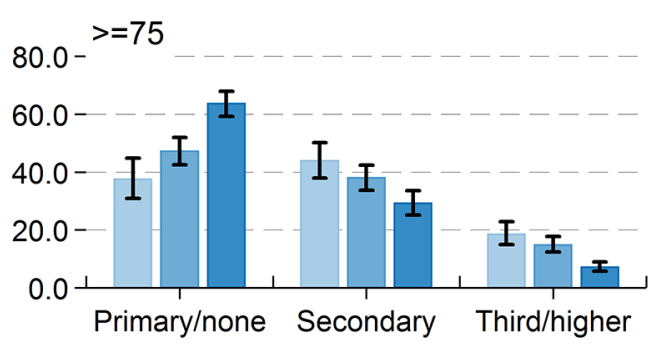

Note. $N=6413$; Missing obs = 12; Error bars correspond to $95 \%$ confidence intervals 
People who had lost all their teeth are less likely to be married than people who had retained all their teeth (50\% versus $73 \%$ ) and more likely to be widowed (35\% versus $9 \%)$, though the proportions who were never married were broadly similar (9-10\%). As expected, the proportions of those widowed increases with age for all dental categories but as seen in Figure 3, even amongst the oldest cohort aged 75 or over, participants with no teeth are more likely to be widowed than those with all their teeth (51\% versus $33 \%$ ).

Figure 3. Marital status by self-assessed dentition status and age

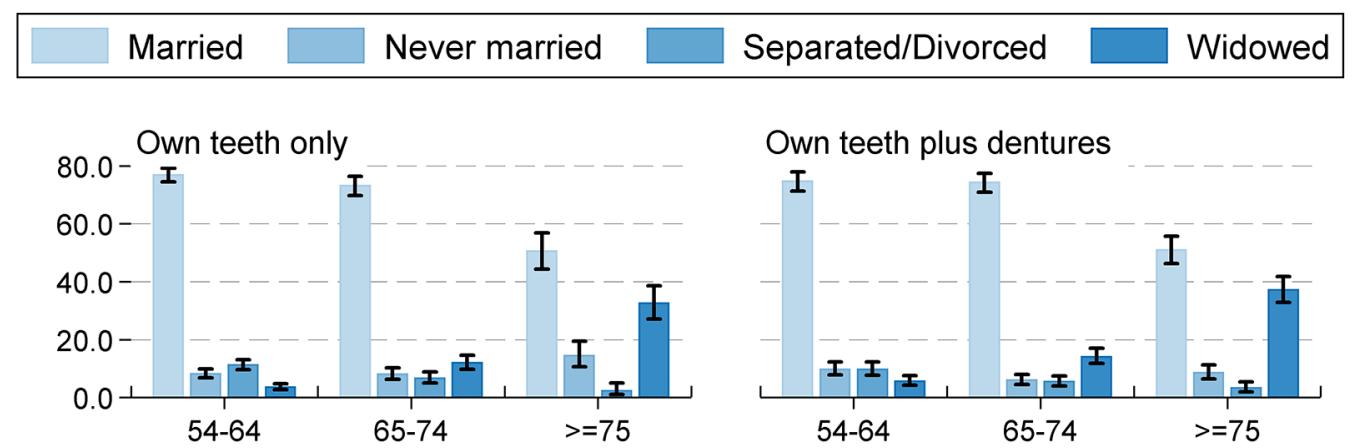

๙ீ

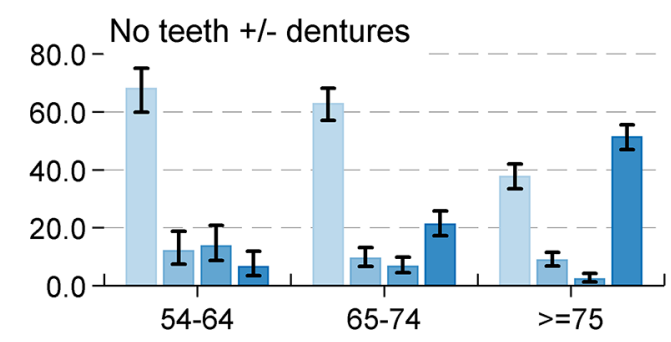

Note. $\mathrm{N}=6415$; Missing obs = 10; Error bars correspond to $95 \%$ confidence intervals 
Dentition status varies by local area. Participants who live in Dublin are more likely to have their own teeth (54\%) than people in other urban areas $(44 \%)$ or rural locations $(41 \%)$.

Dublin residents are half as likely to have lost all their teeth as those living in rural areas (10\% versus $22 \%)$.

Figure 4. Self-assessed dentition status by place of residence

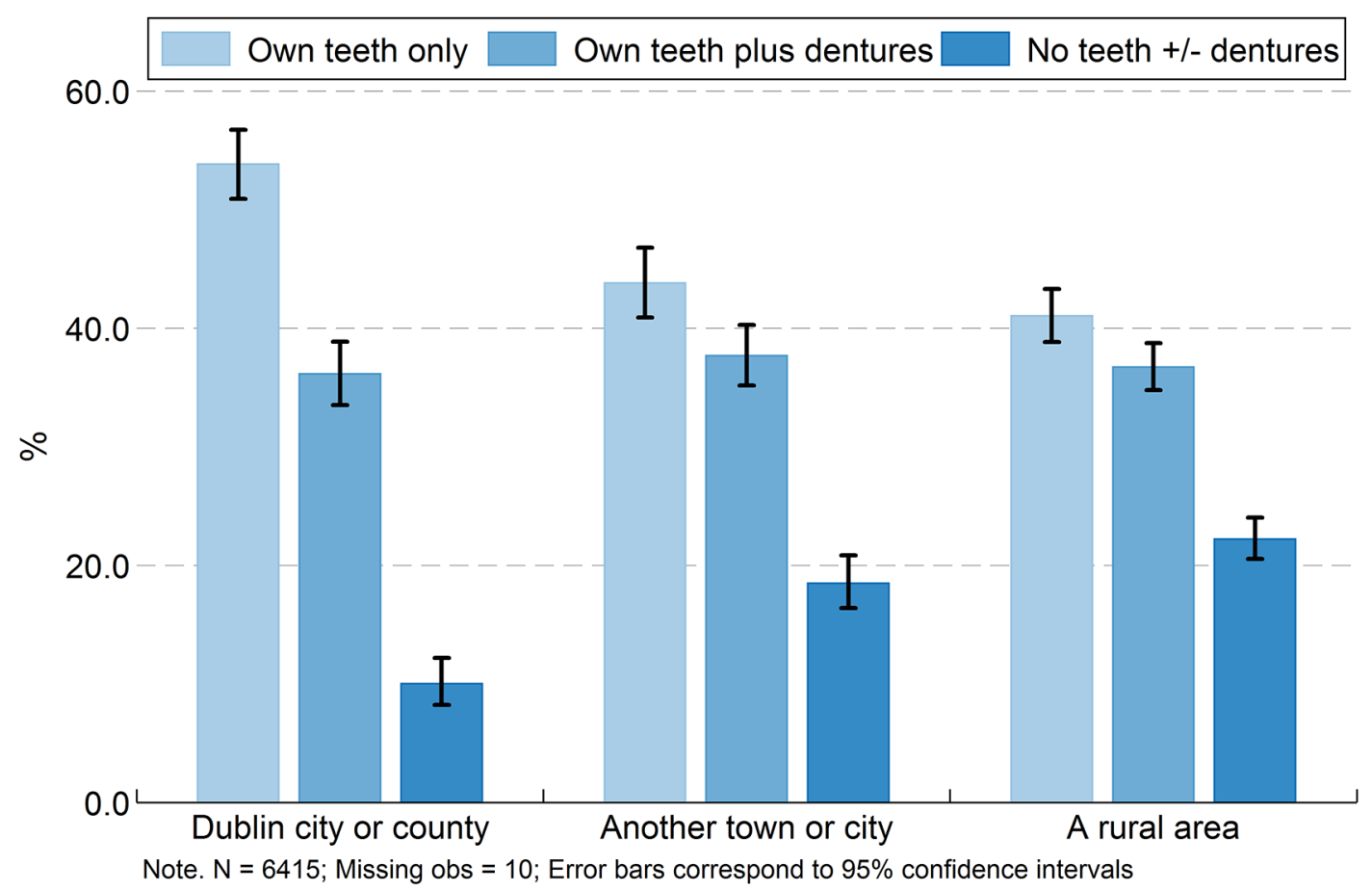


There is also a relationship between holding a medical card and dentition status. Figure 5 shows that older people who have lost all their teeth are more than twice as likely to have a medical card as those with their own teeth ( $83 \%$ versus $37 \%$ ). Because the income threshold for qualifying to receive a medical card is raised for older people aged 70 years or over, the proportion of participants with a medical card increases with age, but a gap remained between the different dentition status groups. While three-quarters $(75 \%)$ of those aged 70 years or over with their own teeth had a medical card, the proportion of those with no teeth or dentures who had a medical card was $91 \%$ in this age group. The persistent difference suggests that disadvantage as well as age is a factor in tooth loss.

Figure 5. Percentage of adults ( $<70$ or $70+$ years) with a medical card, by self-assessed dentition status.
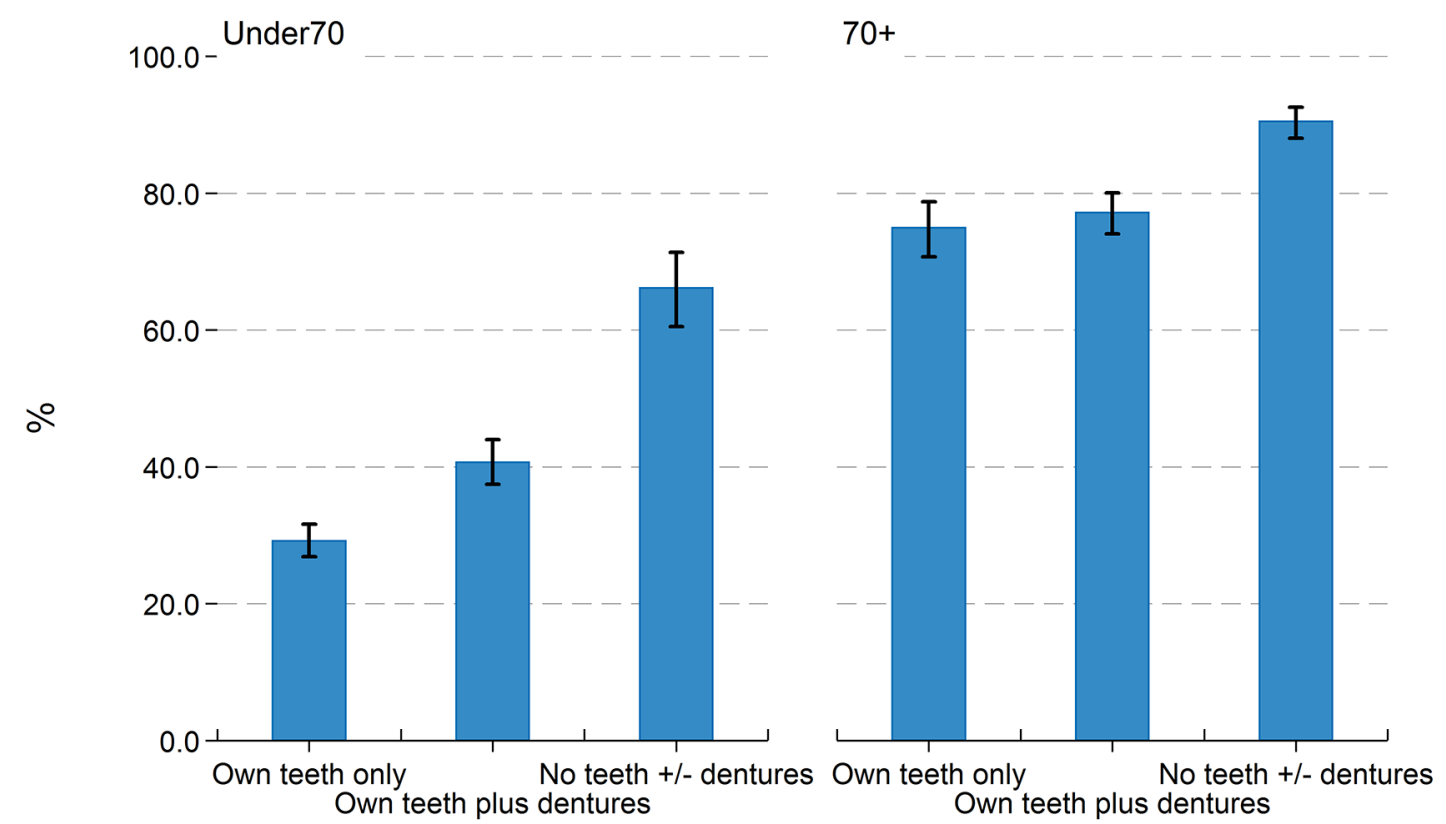

Note. $\mathrm{N}=6401 ;$ Missing obs $=24$; Error bars correspond to $95 \%$ confidence intervals 


\section{Dental healthcare utilisation}

This chapter outlines how dental healthcare is provided in Ireland and describes patterns of dentist attendance among the older population, the types of service used, satisfaction with services and reasons for not using state dental services.

\section{Dental care in Ireland}

Dental health care in Ireland is provided through a mix of private, public and social insurance systems. Free dental care is not universally available but a number of different public dental schemes operate linked to income, age, health and employment status. These are detailed in Appendix 1.

\section{Dentist use}

TILDA participants were asked how often they had visited the dentist in the last few years, with three options: 1) more frequently than every two years; 2) less frequently than every two years; and 3) never. 
Those with no teeth are much less likely to visit a dentist than those who have retained their teeth as seen in Figure 6 . Just $11 \%$ of those with no teeth (+/- dentures) had visited more frequently than every two years compared with $60 \%$ of those with their own teeth. Meanwhile some $43 \%$ of older adults with no teeth have not seen a dentist at all in the past few years compared with $6 \%$ of those with their own teeth.

Figure 6. Frequency of visiting dentist by self-assessed dentition status

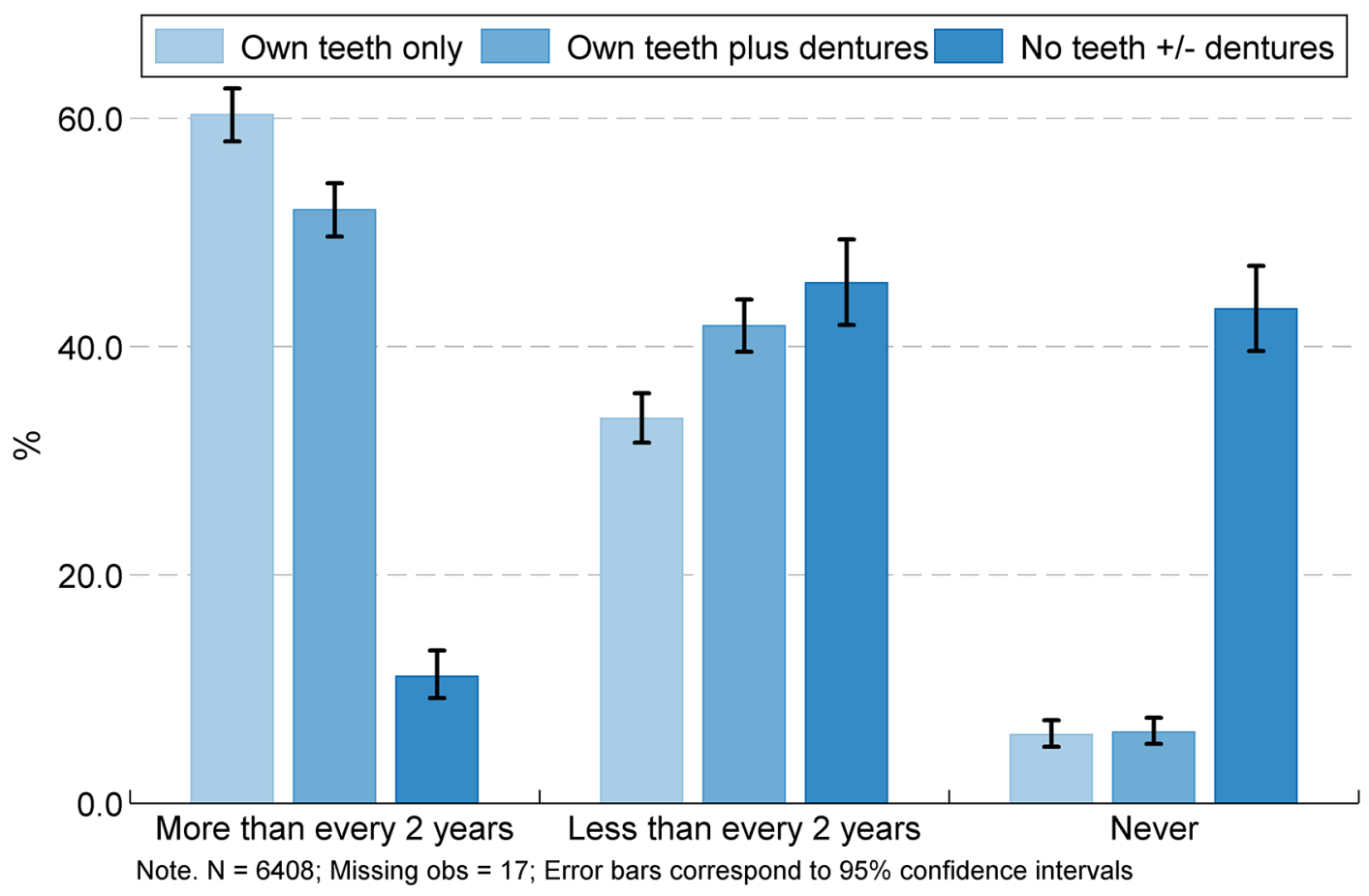


There was also a clear difference in attendance at a dentist by location of residence:

people in rural areas were less likely to attend a dentist regularly than people in Dublin.

Some $44 \%$ of rural-dwellers attended more frequently than every two years, compared to $56 \%$ of Dubliners. The proportion who never attended a dentist ranged from $7 \%$ in Dublin to $15 \%$ in rural areas as shown in Figure 7.

Figure 7 Frequency of visiting dentist by location of residence

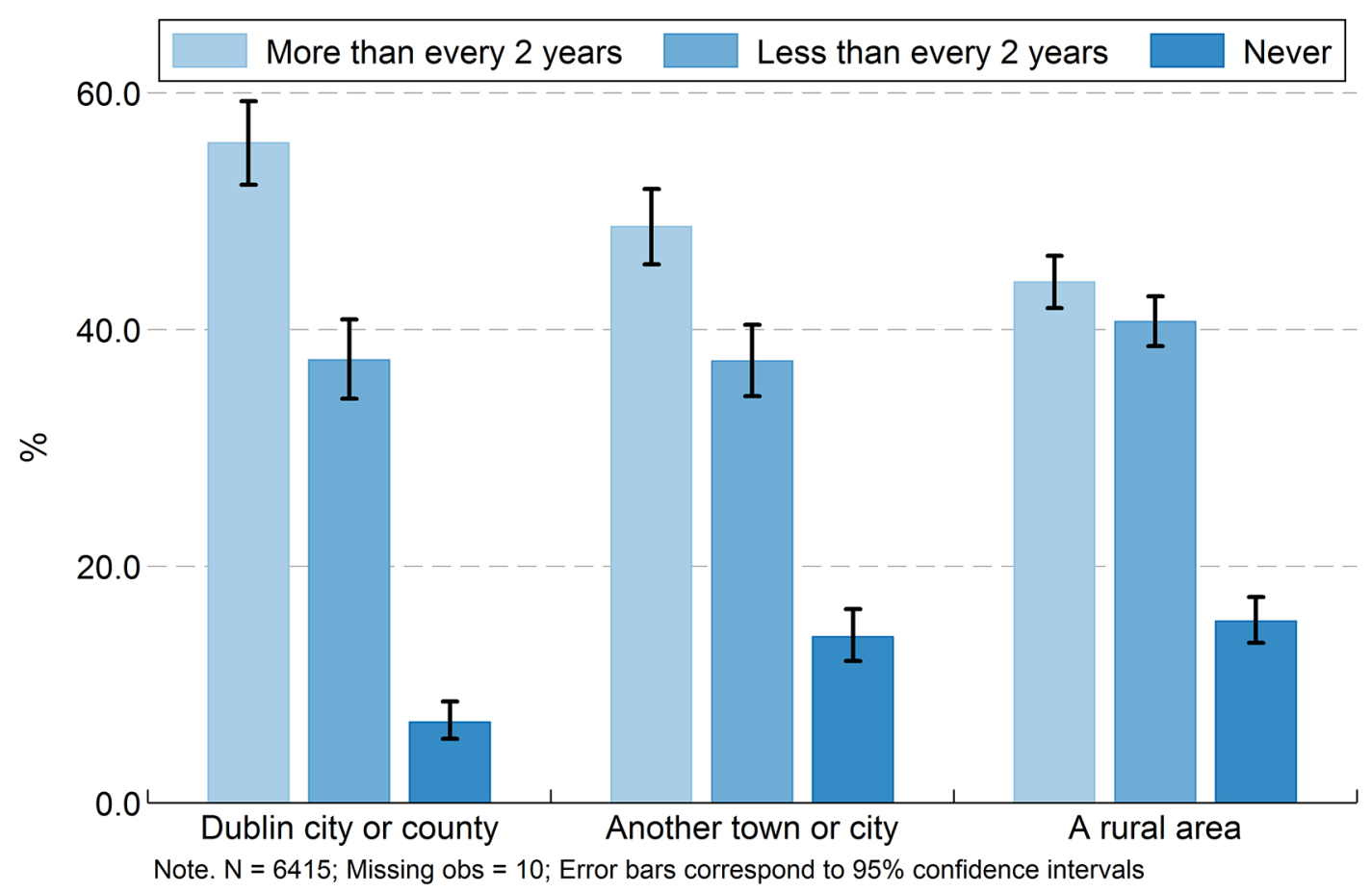


This Dublin/rural difference was also seen by dentition status. People with no teeth were more likely to 'never' attend a dentist if they lived in rural areas (44\%) than if they lived in Dublin (30\%) and, as illustrated in Figure 8, a similar trend was seen amongst those with their own teeth ( $8 \%$ in rural areas versus $4 \%$ in Dublin).

Figure 8. Frequency of visiting dentist by self-assessed dentition status and location of residence

\begin{tabular}{|l|l|}
\hline Dublin city or county $\quad$ Another town or city $\quad \square$ A rural area \\
\hline
\end{tabular}

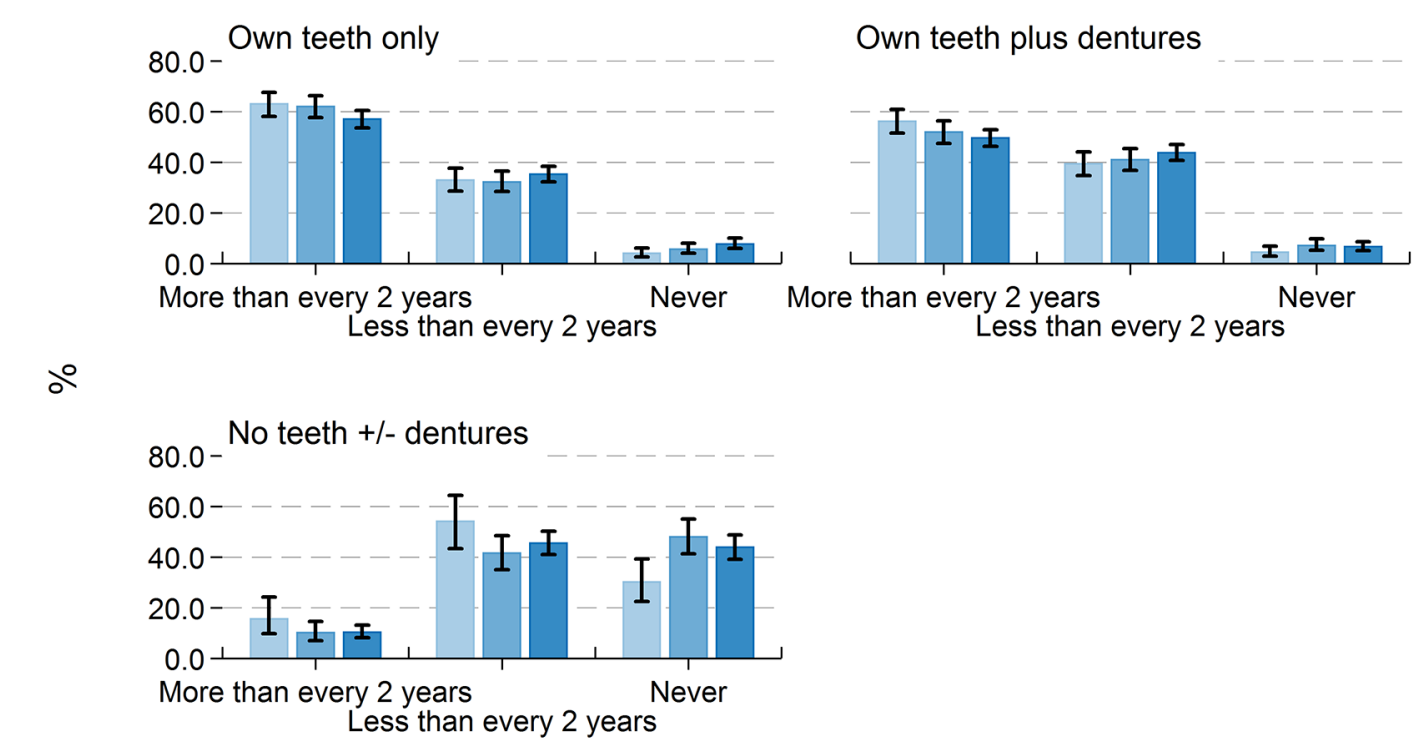

Own teeth plus dentures

Note. $\mathrm{N}=6408$; Missing obs = 17; Error bars correspond to $95 \%$ confidence intervals 
Participants were also asked about where they would go if they needed routine dental care and overall two thirds (66\%), said they would attend a private dentist (Figure 9). This ranged from $78 \%$ of older adults with their own teeth, to $35 \%$ of those with no teeth $+/-$ dentures. Some $45 \%$ of those with no teeth said they would attend a dentist on the medical card scheme compared to $21 \%$ of those with their own teeth. A further $15 \%$ of those with no teeth would opt for a dental technician and $4 \%$ for a HSE dentist at the local clinic. Overall just $1 \%$ would attend a dental hospital (in Dublin or Cork).

Figure 9. Where attend for routine dental care by dentition status

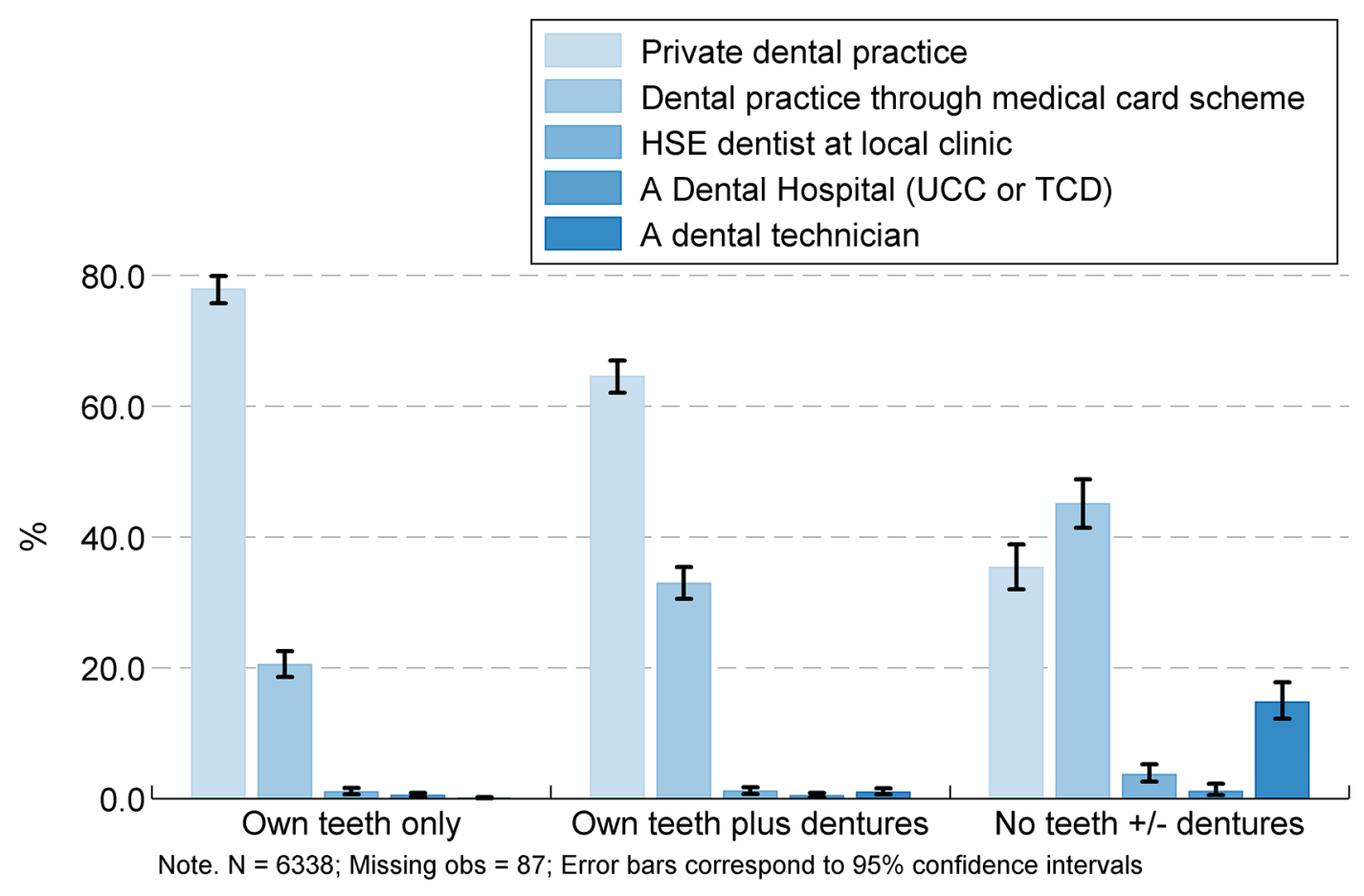

We asked participants if they had used state dental services (which did not have a charge) and just $7 \%$ of participants had used state dental services in the past 12 months. Those with a mix of teeth and dentures are most likely to have used them at $10 \%$ compared with $6 \%$ of those with their own teeth and $4 \%$ of those with no teeth. Amongst those who had used these services $60 \%$ had attended once, $15 \%$ twice and $17 \%$ three times or more in the past 12 months. 


\section{Satisfaction with state dental services}

We asked participants who had used state dental services in the past two years, whether they were satisfied with the service they received. Of those who had used state dental services ( $n=429)$, the majority (94\%) were satisfied with the service they received, and similar proportions were found for all dentition groups. Of the very small number who were not satisfied, the reason was unclear as "dissatisfied for other reason" was the most common option chosen, and a smaller proportion stated the reasons of service "not supplied frequently enough" and dissatisfied because the service was "hard to access".

We also asked participants if they would like state dental services but didn't receive them, what was the main thing preventing them from receiving these service. Amongst this group $(n=265)$ there was a clear difference in the reasons given by the different dentition groups. As shown in Figure 10, almost half (49\%) those with their own teeth who would have liked state dental services said they didn't use them because they were ineligible, 19\% said they were too costly and $8 \%$ said they did not know these services were available.

In contrast, amongst those with no teeth, the large majority of whom have a medical card entitling them to free treatment for most dental care, lack of awareness rather than ineligibility was the major factor preventing access. Nearly half $(48 \%)$ did not know this service was available, $9 \%$ had never heard of it, $23 \%$ said it was too costly and just $6 \%$ said they were ineligible.

Figure 10. Reason for not using state dental services by self-assessed dentition status

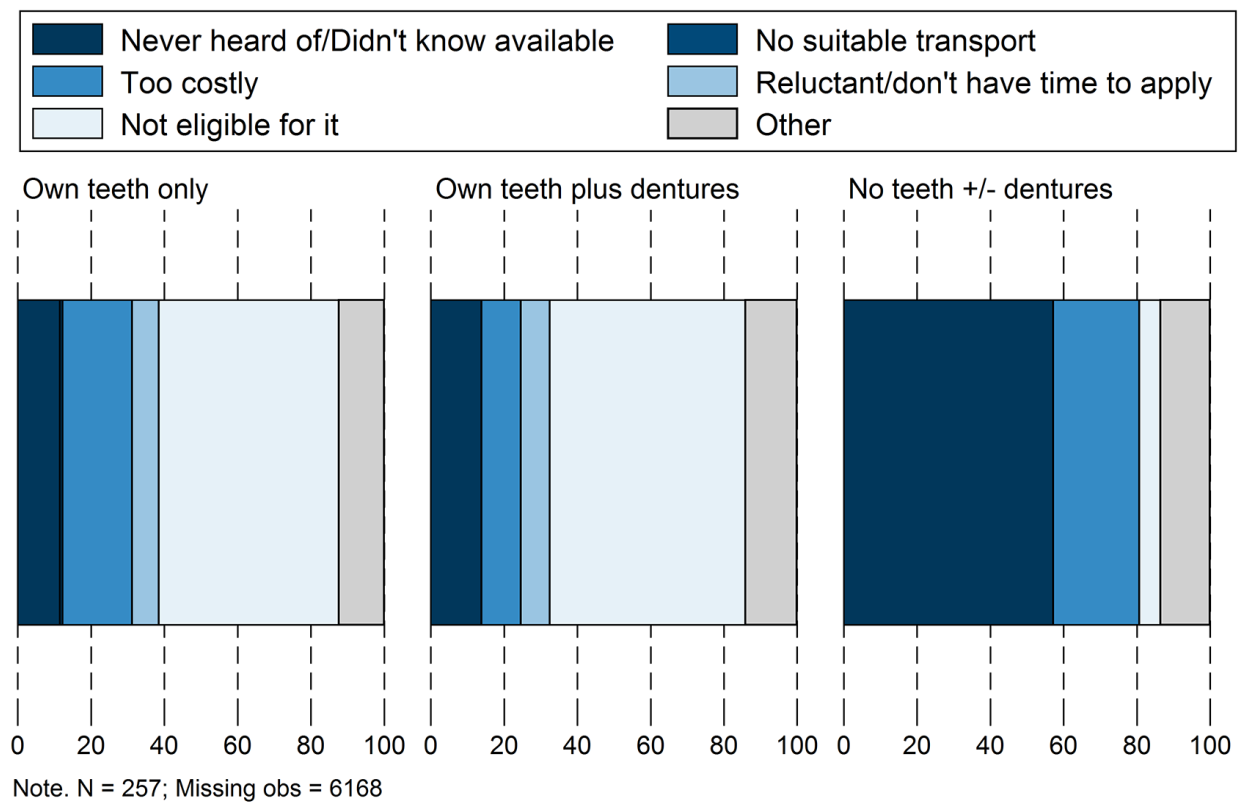




\section{Dentition Status and Physical Health}

The association between dental/oral health and physical health has been of growing interest to scientists as poor oral health has been shown to have an effect on general health (10). In addition to having a bi-directional relationship with some chronic conditions such as diabetes $(13,14)$, a significant association has been found between tooth loss and risk of coronary heart disease (9) and between periodontitis and ischemic stroke (8), while behavioural factors such as poor diet and smoking are also risk factors for poor oral health (10).

This chapter explores the association between physical health and dentition status using a number of self-reported health measures and behavioural indicators that can influence health, including self-reported health, diabetes, cardiovascular conditions and risk factors, polypharmacy and smoking. It also describes self-reported dental health. 


\section{Self-reported physical health}

Participants were asked to rate their health relative to others their own age as one of the following categories; excellent, very good, good, fair or poor. For analysis these categories were regrouped as (1) good health (excellent/very good/good) and (2) poor health (fair/ poor).

Self-rated health varied by dentition status in the older population in Ireland. Figure 11 shows that people who have lost all their teeth are more likely to rate their health negatively than those who have retained them (19\% versus $12 \%)$. Younger participants aged 54 to 64 years with no teeth are the most likely to rate their physical health negatively.

Figure 11 Proportion with poor self-rated health by self-assessed dentition status, age and sex

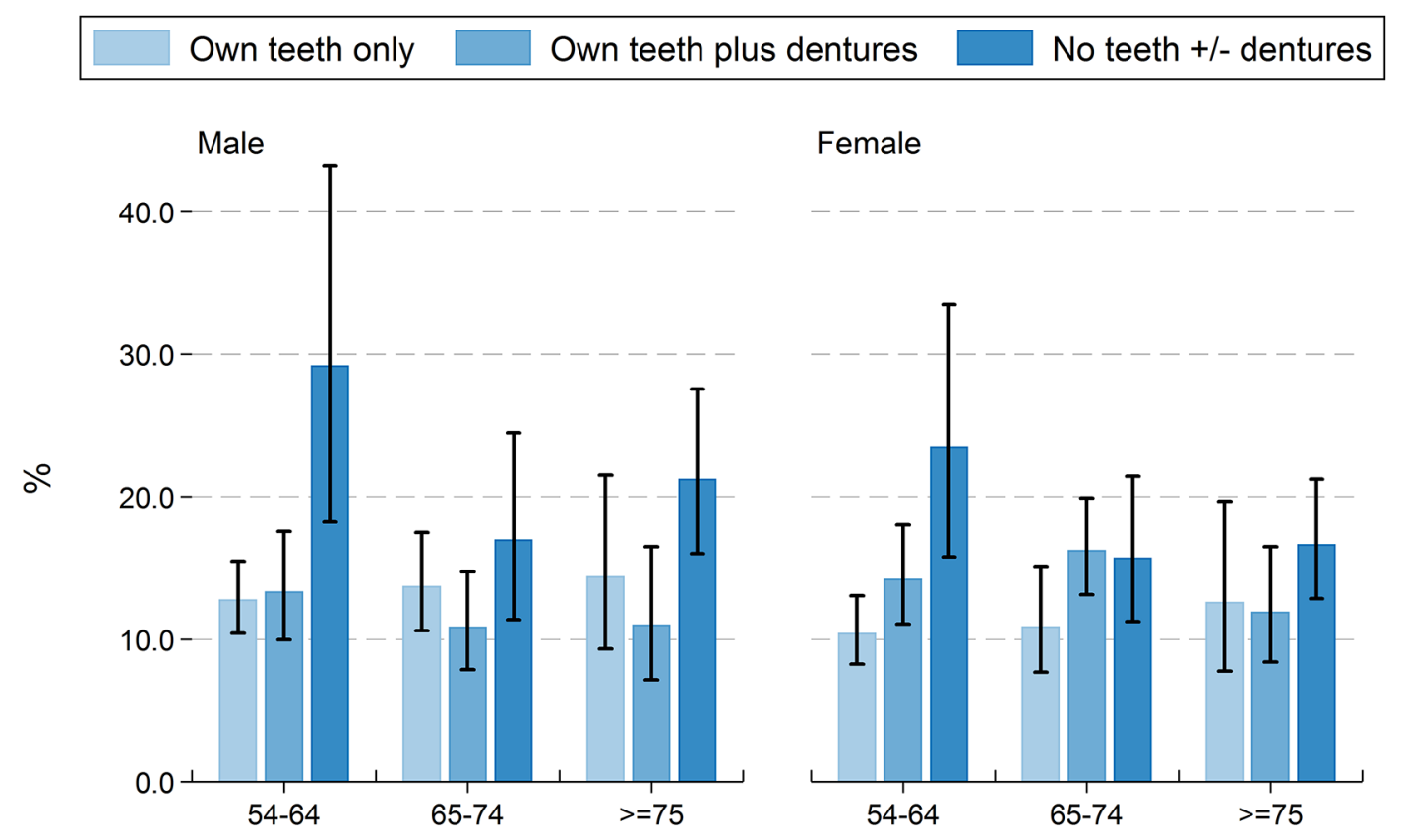

Note. $\mathrm{N}=6292$; Missing obs = 133; Error bars correspond to $95 \%$ confidence intervals 


\section{Cardiovascular conditions}

As cardiovascular disease (CVD) is the highest cause of death in Ireland, the prevalence of CVD was examined for different dental health groups. Participants were asked if they had been diagnosed with any of a number of cardiovascular conditions (angina, heart attack, heart failure, stroke, TIA, heart murmur) or cardiovascular risk factors (high cholesterol, hypertension, diabetes). As a particular link between oral health and diabetes has been established (13), it was analysed separately to other heart conditions/risk factors.

\section{Diabetes}

People with no teeth were more likely to have been diagnosed with diabetes (13\%) than those with their own teeth (8\%), though once age was taken into account the difference was only significant for those in the 65 to 74 age group (17\% versus $11 \%$ ).

Figure 12. Diabetes by dentition status and age

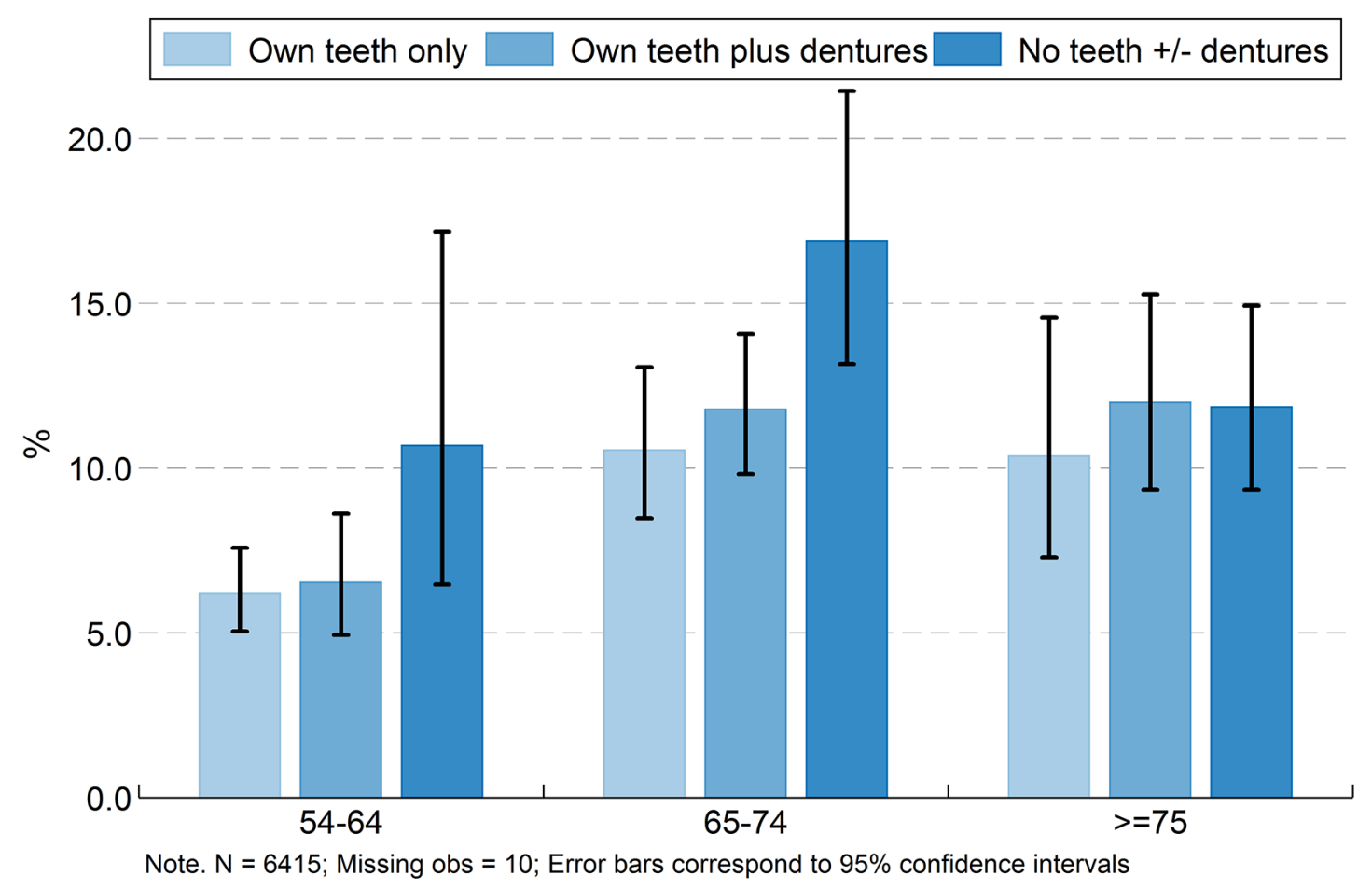


The prevalence of cardiovascular conditions (angina, heart attack, heart failure, stroke, TIA, heart murmur) and other cardiovascular risk factors (high cholesterol, hypertension) did not differ significantly for the different dentition groups.

\section{Medication use}

The association between dental status and medications was also explored as many medications used to treat systemic disease cause a reduction in salivary flow which may increase the risk of root caries and poor oral health, and this risk increases the more medications are taken $(6,15)$.

Older adults with no teeth are twice as likely to be taking five or more medications (polypharmacy) as those who have teeth (42\% versus $20 \%$ ) and even when adjusted for age, this difference was seen for the group aged 54 to 64 years (Figure 13). This may be due to worse general health in the edentulous group, but in this younger cohort, it could also indicate a link between loss of teeth and a reduced saliva flow as a side-effect of medications.

Figure 13. Polypharmacy by self-assessed dentition status and age

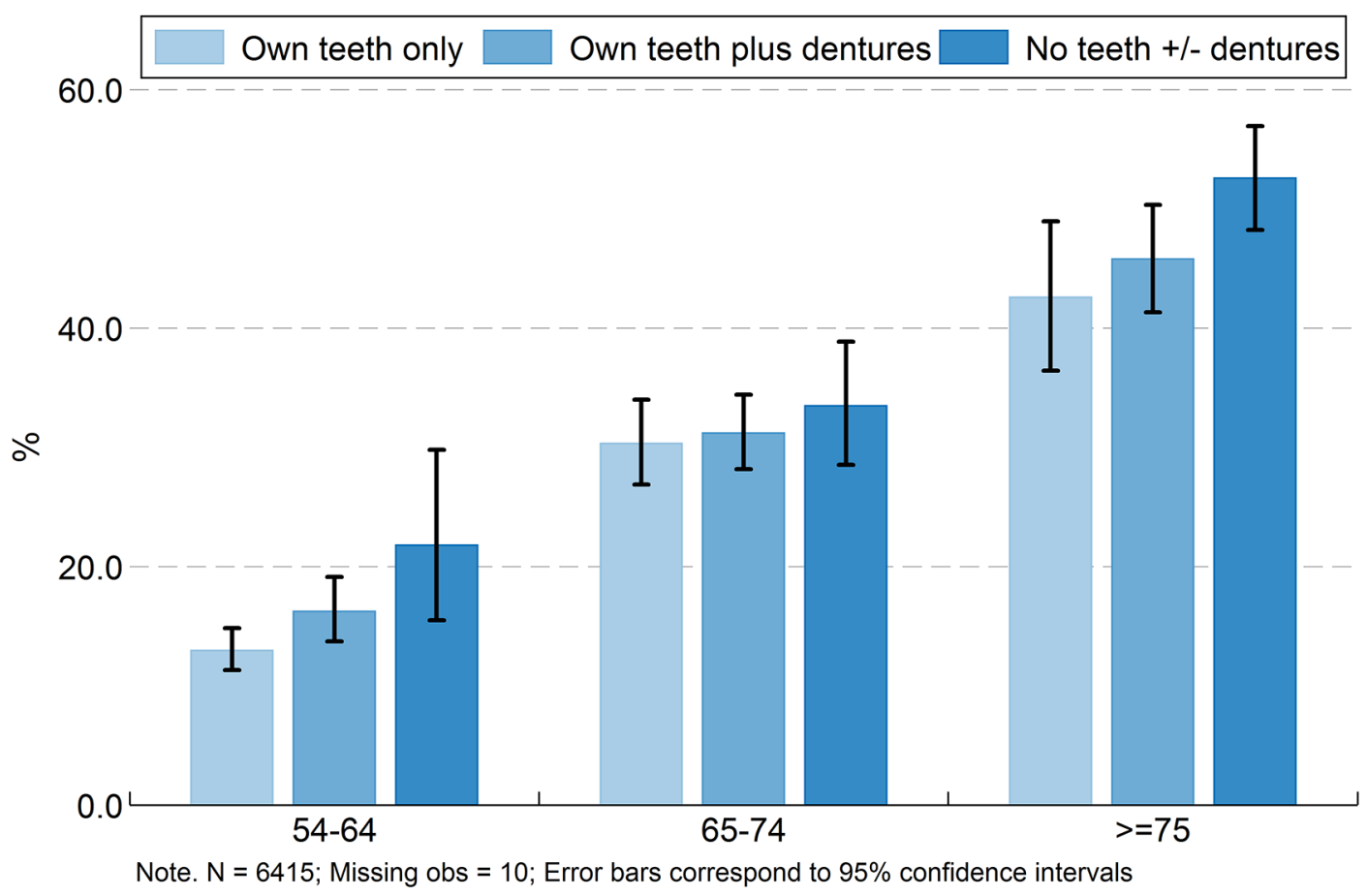




\section{Smoking}

Smoking is a known risk factor for periodontal disease and has been associated with increased tooth loss (6). Participants were asked if they currently smoked, were past smokers or never smoked.

Older adults with no teeth are more likely to be current smokers than those with their own teeth (19\% versus $13 \%$ ) and less likely to have never smoked (38\% versus $45 \%$ ) but these differences were only significant for the younger cohorts 54 to 64 and 65 to 74 years. This suggests that smoking could be a more of a factor in tooth-loss in this cohort rather than the multifactorial tooth loss more commonly seen in older age groups. As seen in Figure 14 , the proportions of ex-smokers is similar for all dentition groups (40-42\%).

Figure 14. Smoking history by age and dentition status

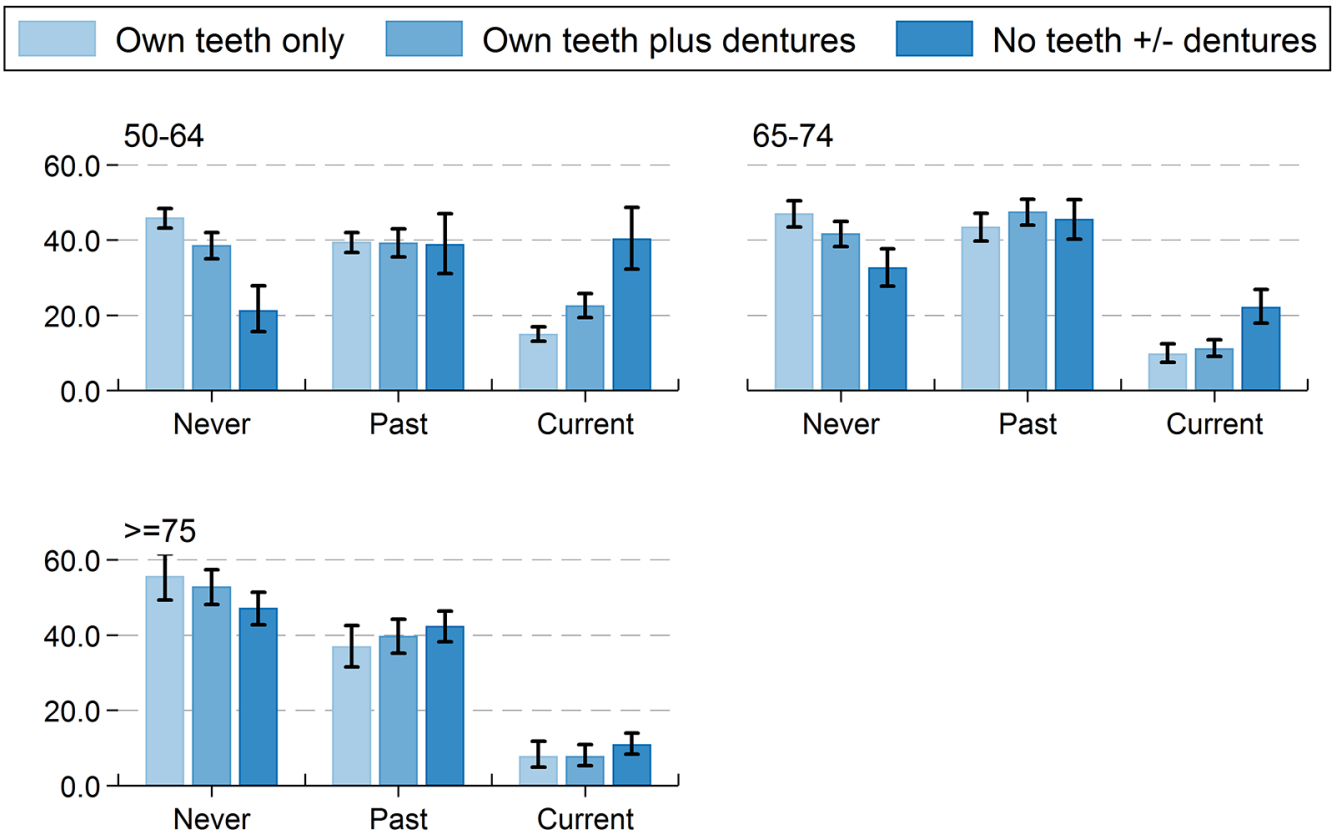

Note. $N=6409$; Missing obs = 16; Error bars correspond to $95 \%$ confidence intervals

\section{Disability}

Participants were also asked if they had any difficulties with carrying out normal daily activities such as dressing, washing or eating. These are known as Activities of Daily Living (ADL), and are often used by health providers as a measure of disability. Those with no teeth are twice as likely to report an ADL as those with their own teeth (13\% versus 
$5 \%)$ or those with a mix of dentures and their own teeth $(6 \%)$, however this difference was not significant when examined within age groups, indicating that these were age-related changes rather than associated with dental health.

\section{Oral Health}

Participants were asked to rate their own oral health (mouth, teeth and/or dentures) on a five-point scale as one of the following: excellent, very good, good, fair or poor. For analysis these categories were grouped; (1) good oral health (excellent/very good/good) and (2) poor oral health (fair/poor).

Participants with all their own natural teeth had the best self-rated oral health. However, as illustrated in Figure 15, participants who had full dentures had a relatively positive opinion of their oral health with only $11 \%$ rating it negatively, compared with $26 \%$ of those with a mix of teeth and dentures. Similar trends were seen for all ages and a broadly similar trend was seen for both men and women.

Figure 15. Poor/fair self-rated oral health by teeth and age

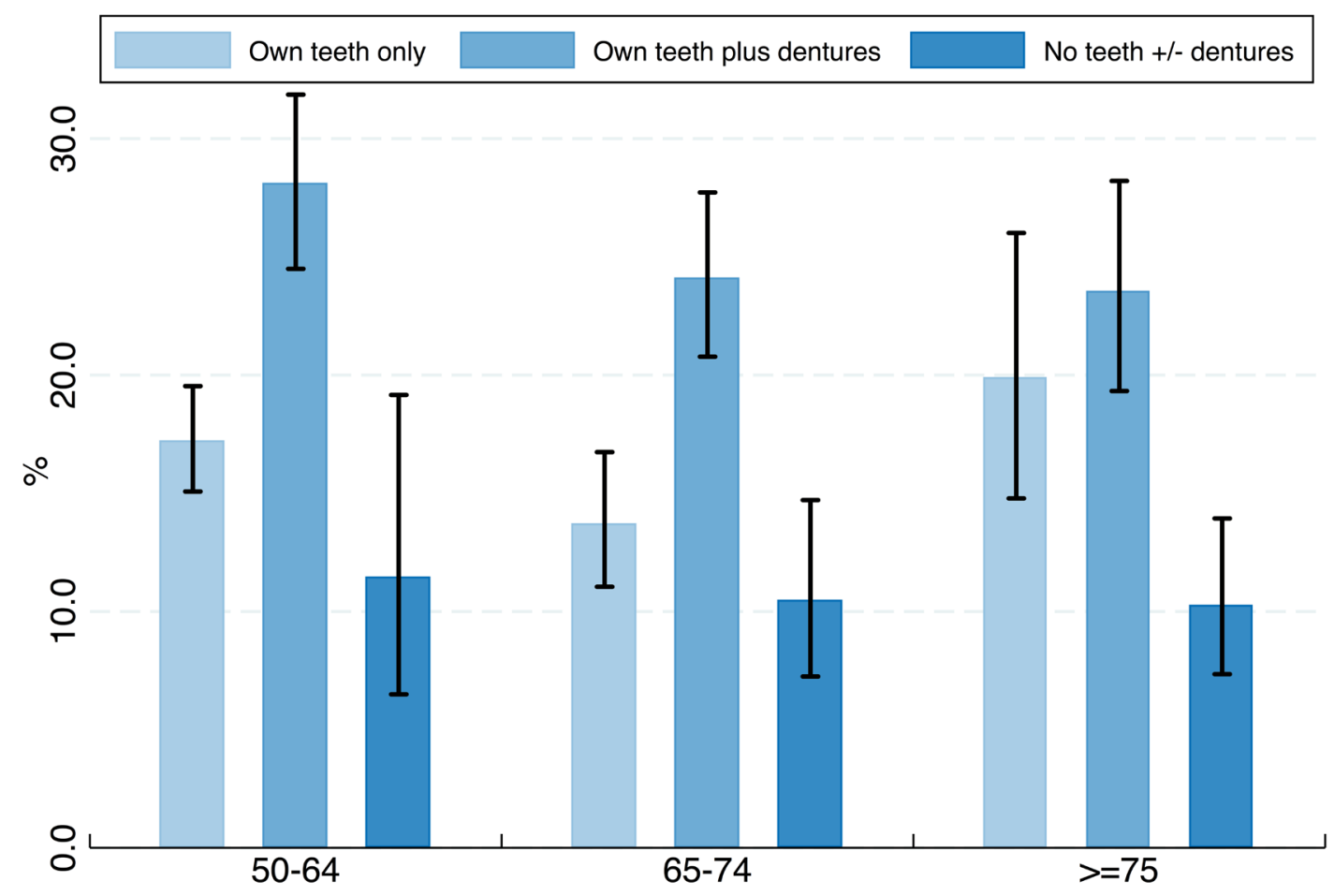




\section{Dentition Status and Wellbeing}

In order to explore the impact of oral health on wellbeing and social activity we used a number of measures. These included specific questions in TILDA on problems caused by mouth, teeth or dentures such as eating, speaking and laughing, as well as general questions on mood, quality of life, social participation and loneliness.

\section{Difficulties caused by mouth/teeth/dentures}

Participants were asked whether in the last six months they had any problems with their mouth, teeth or dentures which had caused (1) difficulty eating food, (2) difficulty speaking clearly, (3) problems with smiling, laughing and showing teeth without embarrassment, (4) problems with emotional stability, for example, becoming more easily upset than usual or (5) problems enjoying the company of others such as family, friends or neighbours.

Overall $6 \%$ had experienced at least one difficulty with little variation by dentition status, from just $5 \%$ of those with all their own teeth to $7 \%$ of those with no teeth (Figure 16).

Figure 16. Difficulty caused by mouth/teeth/dentues by seft-assessed dentition status and sex

\begin{tabular}{|l|l}
$\square$ Own teeth only $\square$ Own teeth plus dentures $\square$ No teeth $+/$ - dentures \\
$\square$
\end{tabular}

$$
60.0^{-}
$$

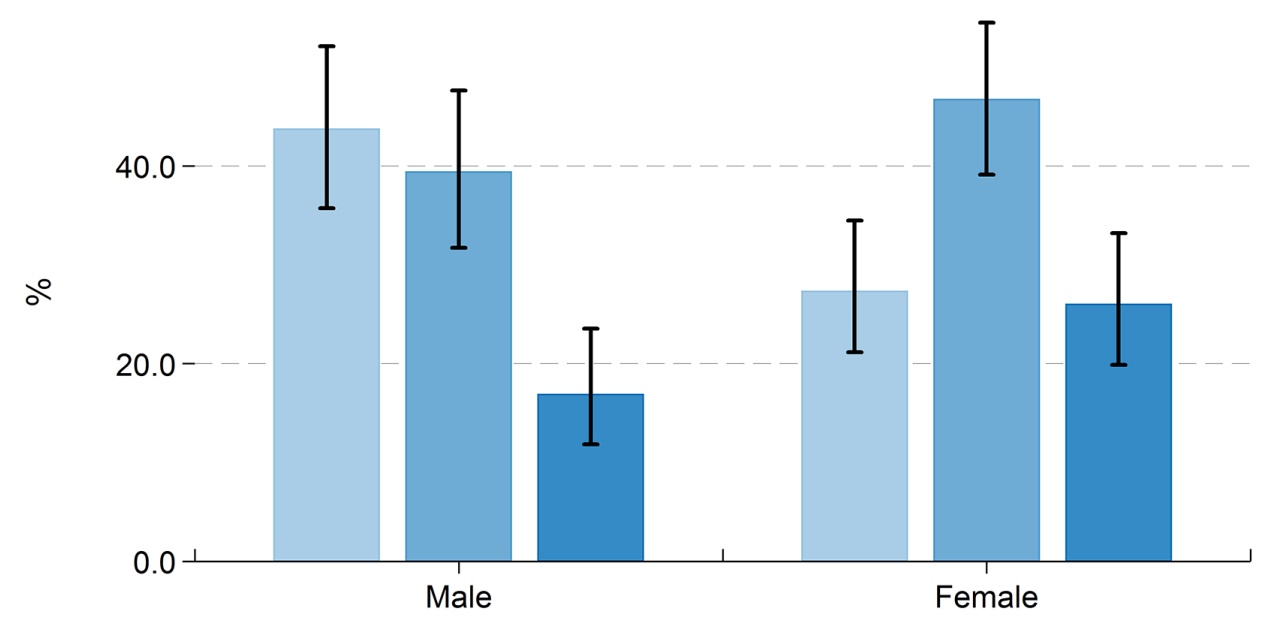

Note. $\mathrm{N}=374$; Missing obs $=1$; Error bars correspond to $95 \%$ confidence intervals 
Eating was the most commonly reported problem with $6 \%$ of those with no teeth with or without dentures reporting difficulty with this compared to $3 \%$ of those with all their own teeth and $5 \%$ of those with full or partial dentures. The next most common problem for those with no teeth or dentures is smiling/laughing/showing teeth $(2 \%)$ and speaking clearly $(1 \%)$. Tiny proportions $(<1 \%)$ reported dental-related problems with emotional stability or enjoying company. Three quarters of those who encountered problems report just one issue, with $15 \%$ encountering two.

\section{Depressive Symptoms}

Depressive symptoms were assessed in TILDA using the short 8-item version of the Centre for Epidemiological Studies Depression (CES-D) scale. This measures the frequency that respondents have experienced a range of depressive symptoms within the past week. It has 8 items which are summed to give a total score ranging from 0 to 24 with higher scores indicating increased depressive symptoms. The average CES-D8 score among participants aged 54 years or older is 3.4 .

Those with no teeth had higher depression scores than those who had retained their teeth, and the gap was widest in the younger 54 to 64 year age group (4.5 versus 3.3 ) as seen in Figure 17 below.

Figure 17. Depressive symptoms by self-assessed dentition status, age and sex

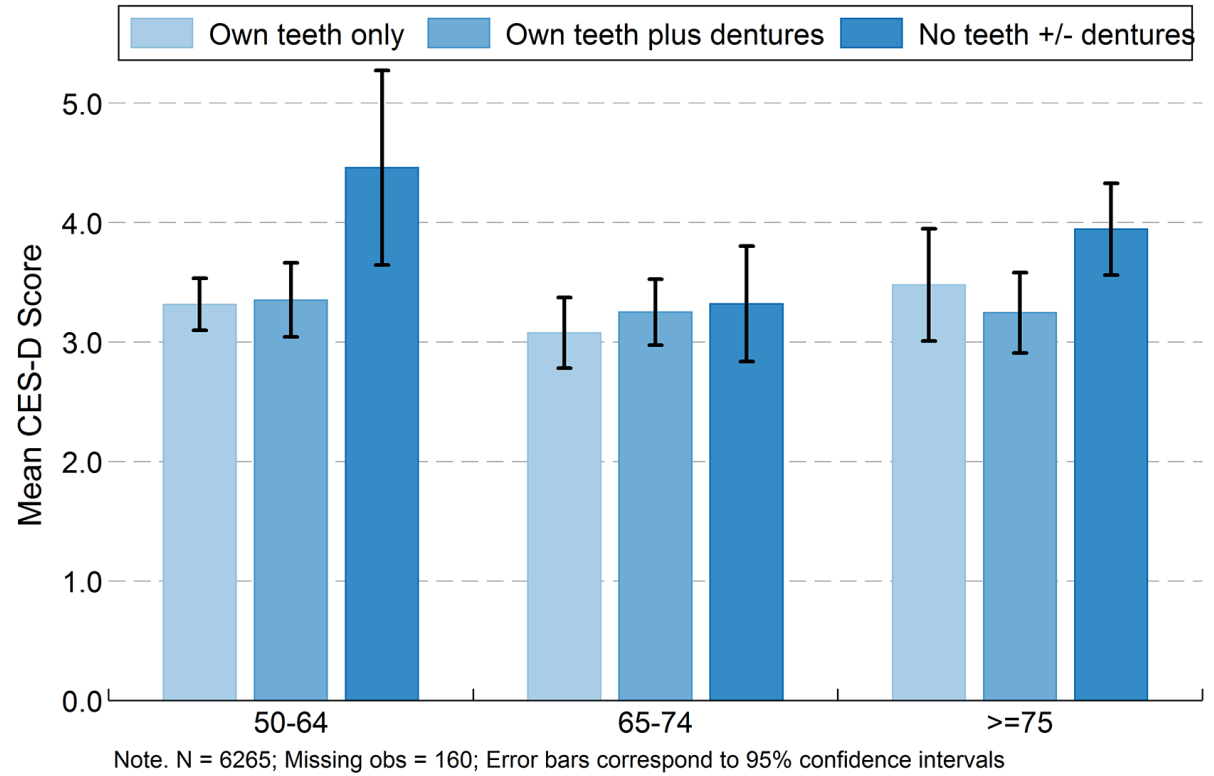




\section{Loneliness}

Symptoms of loneliness were assessed using the University of California-Los Angeles (UCLA) loneliness scale, in which scores can range from 0 (not lonely) to 10 (extremely lonely). Five questions to assess loneliness were asked including "How often do you feel left out?" and "How often do you feel in tune with the people around you?" with three response options: 'often', 'some of the time' or 'hardly ever or never'. The average score of older adults was 1.8. Those with no teeth $+/$ - dentures had more symptoms of loneliness than those with their own teeth (2.1 versus 1.8$)$ particularly in the younger age group aged 54 to 64 years where the mean score for those with no teeth was 2.3 (Figure 18).

Figure 18. UCLA loneliness score by self-assessed dentition status, age and sex

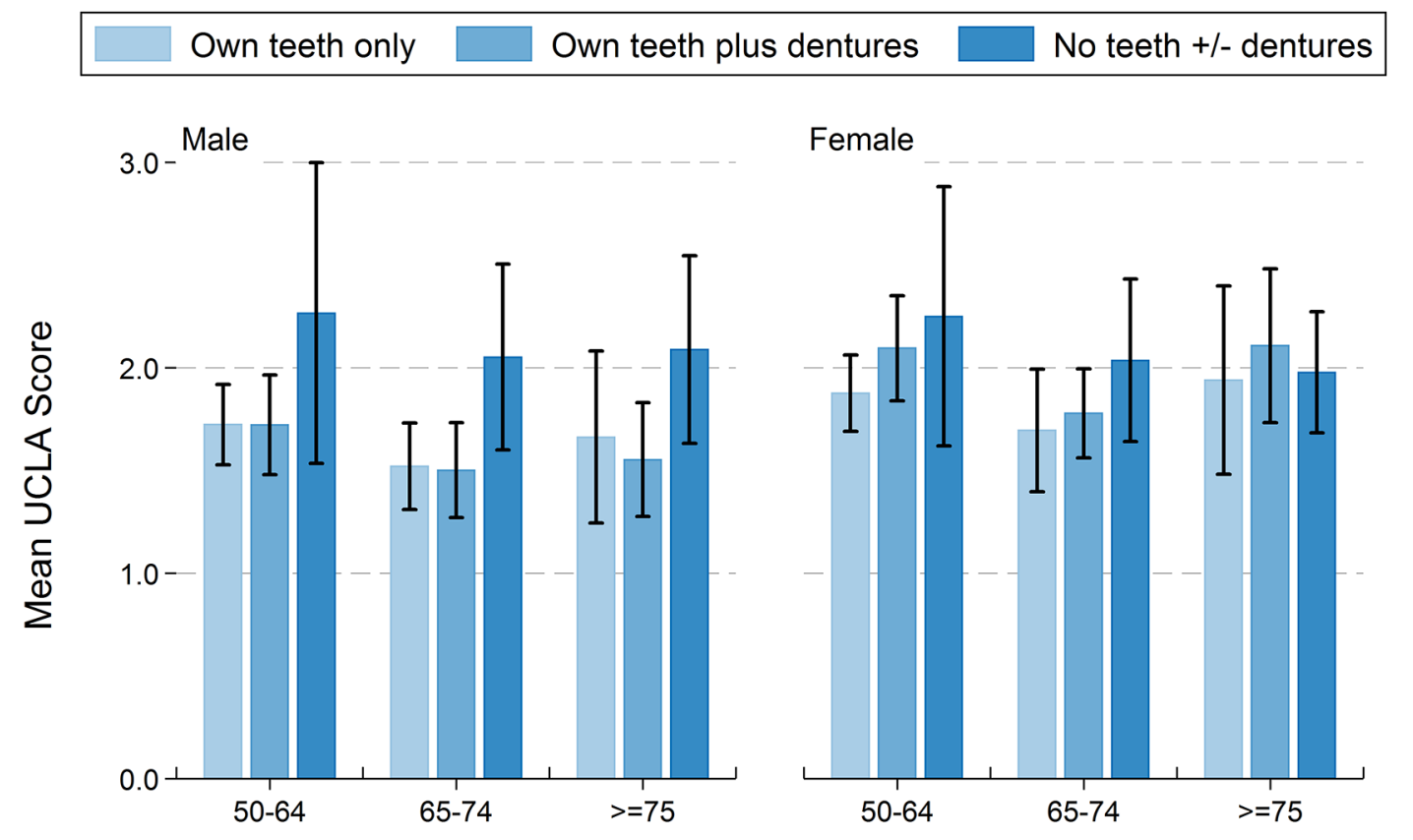

Note. $\mathrm{N}=5201$; Missing obs = 1224; Error bars correspond to $95 \%$ confidence intervals 


\section{Active social participation}

Participants were asked about social activities they take part in, including going to films, plays or concerts, attending classes or lectures, playing cards, bingo, games, going to the pub, eating out, or taking part in sport or exercise. Those who reported that they did any of these activities at least once a week were classified as being involved in active social participation.

Older adults with no teeth had reduced active social participation compared to those with their own teeth (64\% versus $78 \%$ ). The difference was most pronounced in women aged 75 years or over where the proportion with active social participation fell from $71 \%$ of those with their own teeth to $54 \%$ of those with none (Figure 19). This may be consistent with the finding that older people with no teeth are more likely to be lonely (Figure 18).

Figure 19. Active social participation by self-assessed dentition status, age and sex

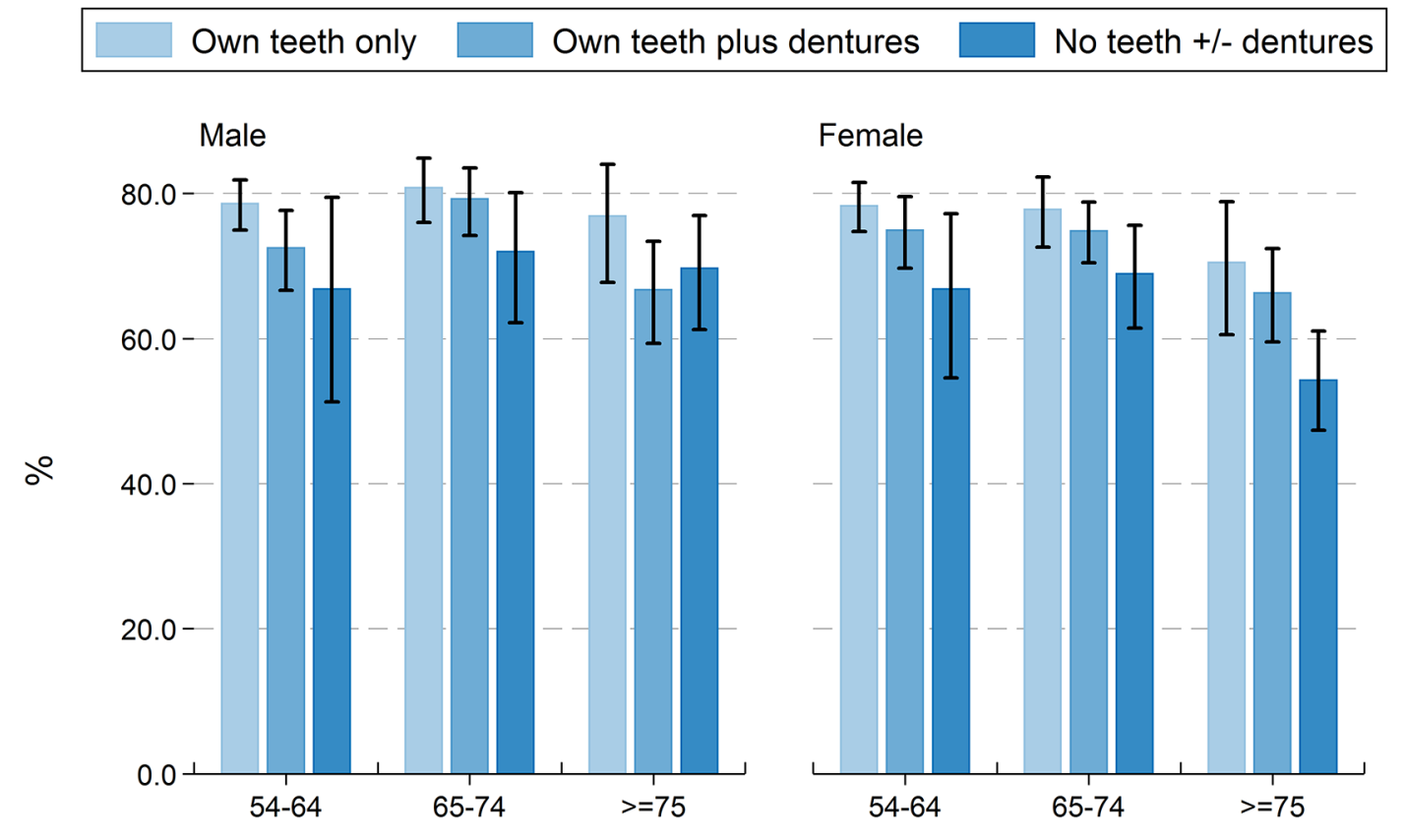

Note. $N=5348$; Missing obs = 1077; Error bars correspond to $95 \%$ confidence intervals 


\section{Quality of life}

Quality of life is assessed in TILDA using the 12-item self-report measurement CASP 12 scale. This scale looks at four different domains of life quality; Control (the ability to participate in one's environment), Autonomy (freedom from the unwanted interference of others), Self-realisation (the fulfilment of one's potential) and Pleasure (happiness or enjoyment derived from engaging with life). Twelve items are used to form a scale which ranges from 0 (no quality of life) to 36 (excellent quality of life). Each item is scored from 0 to 3 and summed to give an overall score with a range of 0-36, and higher scores indicating better quality of life. The average score for older adults in Ireland is 27.

Older adults with their own teeth have a higher mean CASP-12 quality of life score (27) than those who have neither teeth nor dentures (23) or those who have full dentures (26). As Figure 20 shows this trend is particularly pronounced in edentulous women whose quality of life score is 21 .

Figure 20. CASP-12 Quality of life score by self-assessed dentition status and sex

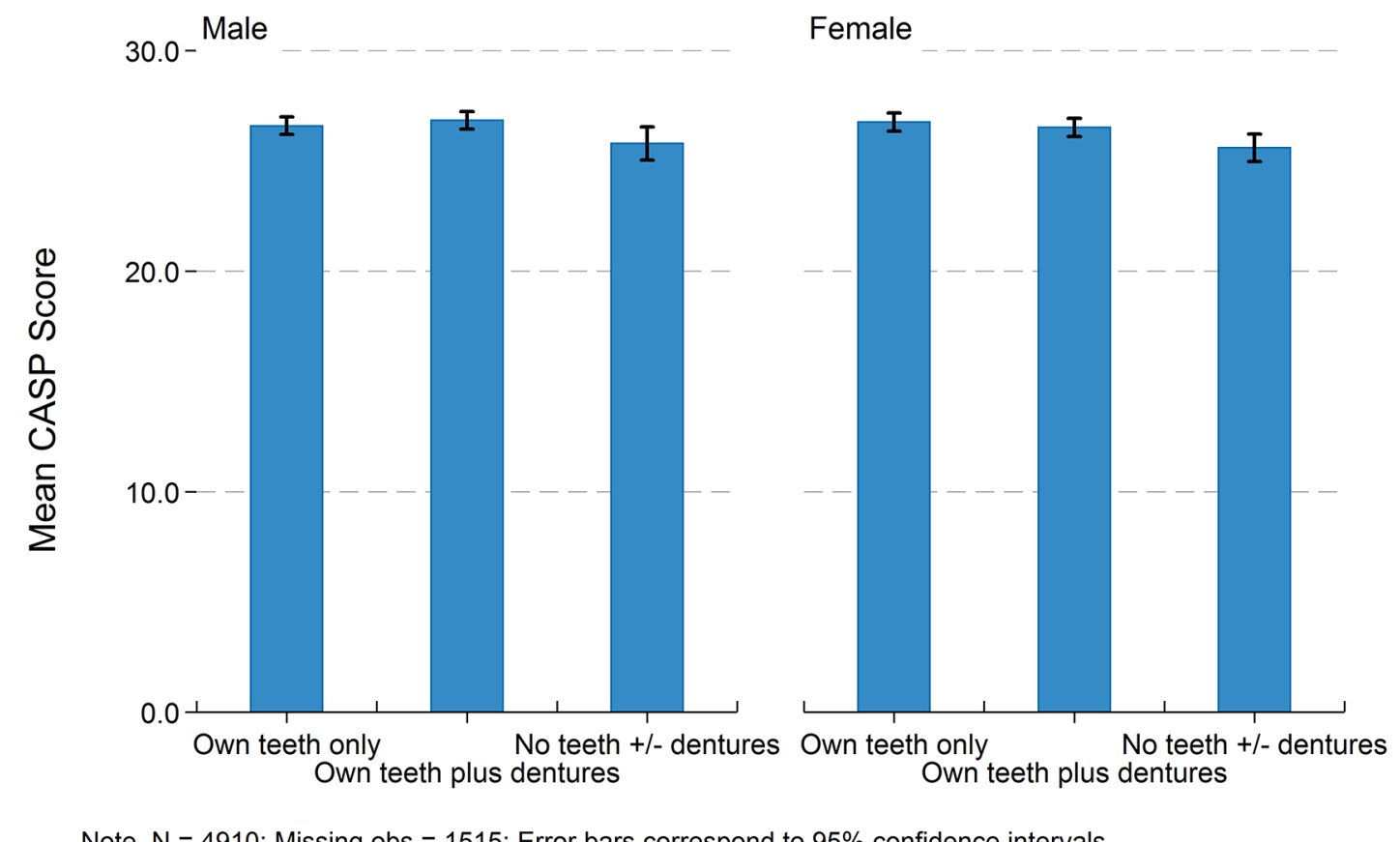

Note. $\mathrm{N}=4910$; Missing obs $=1515$; Error bars correspond to $95 \%$ confidence intervals 


\section{Conclusions}

In this report, we examined the dental status of older adults in Ireland, whether they used, and what they thought of dental services, and investigated how the quality of their oral health affected their mood, social participation and quality of life. We found that a large proportion of older Irish adults had no teeth, and these were replaced with either full or partial dentures, although a small minority had neither teeth nor dentures. There was a marked reduction in tooth loss among the younger old (54 to 64 years) which indicates improved oral health, possibly due to better dental services or the impact of fluoridation of water supplies since the 1960s. Dental status was related to both quality of life and mood, and those who had not retained their own teeth had lower quality of life, higher depressive symptoms and more loneliness. They were also less socially active than their peers who had retained their own teeth.

\section{Health Findings}

People who have lost all their teeth are more likely to rate their physical health negatively, particularly in the 54 to 64 age group, which could indicate either worse general health or stigma associated with tooth loss, which has become less common in younger cohorts.

Diabetes is also more common among edentulous adults aged 64 to 75 years which has implications for ongoing management of their health as oral disease can have a negative impact on the regulation of diabetes.

The fact many older people with no teeth are on multiple medications could be a sign of generally poorer health or this polypharmacy could also be a contributory factor to tooth loss due to the side effect of reduced salivary flow. This highlights the need to ensure oral health is given greater priority amongst those with multiple health conditions.

An important finding to note is that adults aged 54 to 64 years with no teeth are much more likely to be current smokers than similar aged adults who have retained their own teeth. This indicates that smoking may be contributing to tooth loss in this younger cohort rather than the historic practice of widespread extractions, which will have been more common in the older generation. 
Wellbeing, mood and social participation

Older people with no teeth experience increased depressive symptoms relative to those who have retained their teeth and they report lower quality of life. Older people who have lost their teeth are also less likely to participate weekly in active and social leisure activities than those with teeth - an important finding as previous research has shown that doing so is associated with higher quality of life (16). They also experienced more loneliness, even in the younger (54 to 64 years) age group. This reduced social participation and wellbeing could be a result of worse physical health, but given that those who have full dentures enjoy a better quality of life than those without them suggests that providing improved dental and denture care to this cohort could be important in helping them maintain social activity with all its attendant benefits.

\section{Policy Implications for dental services}

The use of dental health services is important to ensure oral health, and the Department of Health has committed to improved oral hygiene and preventive measures in its Statement of Strategy 2016-2018. Indeed early intervention and promoting oral hygiene have been targeted as key dental health goals. Additionally, alongside commitments to extending its dental health programme for schoolchildren and extending dental treatment benefits for insured workers, there is a target in the current Programme for Government to introduce a preventive dental health package for medical cardholders, which includes a high proportion of older people (17).

We found in this study that among older people, there are wide discrepancies in the use of dental services by location and by dentition status. There was a particularly large discrepancy in the frequency of attending a dentist between people living in Dublin and in rural areas, suggesting services may be harder to access in the latter. The fact that older people in rural areas are much more likely to have lost all their teeth could be a consequence of more limited availability of dental services, or it could be related to the fluoridation of public water supplies, given water supplies in rural areas are more likely to be from non-fluoridated, private sources (12). In either case it suggests greater accessibility to dental services is needed for this cohort.

The Department of Health has also made a commitment to introduce a new National Oral Health Policy (18) following an in-depth review of existing services and needs. This review has highlighted concerns about oral health inequalities and the potential need for new measures to treat older adults in care setting and in the home (19). While most dental 
services in Ireland are accessed privately, possession of a medical card entitles holders to the use of free, state dental services. However, despite the fact that half of participants have a medical card rising to over $80 \%$ of the oldest group, the use of state dental services is low with only $7 \%$ reporting using them in the last 12 months. A majority of participants say they would attend a private dentist if they needed routine dental care. Use of state dental services is particularly low amongst those with no teeth, and even among those who would like to avail of them, the majority report that they have never heard of them, do not know they are available, or believe they would be too costly. This suggests more effort could be put into informing and assisting older people in how to access state dental services. It could also indicate variable availability in some areas, particularly given the discrepancies already noted in dental care attendance and outcomes between Dublin and rural areas. 


\section{References}

1. Locker D, Clarke M and Payne B. Self perceived Oral Health Status, Psychological Wellbeing and Life Satisfaction in an Older Adult Population. Journal of Dental Research. 2000; 79:4.

2. Sischo $L$ and Broder HL. Oral Health-related Quality of Life: What, Why How and Future Implications. Journal of Dental Research. 2011; 90(11): 1264-1270.

3. Gerritsen AE, Allen PF, Witter DJ, Bronkhorst EM and Creugers NHJ. Tooth loss and oral health-related quality of life: a systematic review and meta-analysis. Health and Quality of Life Outcomes. 2010;8:126.

4. Tan H, Peres KG, Peres M. Retention of Teeth and Oral Health-Related Quality of Life. Journal of Dental Research. 2016; 95:12: 1350-1357.

5. Rodriguez SM, Oliviera AC, Vargas AMD, and Morreira ANM. Implications of Edentulism on Quality of Life among Elderly. Int. J. Environ. Res. Public Health 2012; 9(1): 100-109.

6. Whelton H, Crowley E, O'Mullane D, Woods N, McGrath C, Kelleher V, Guiney H, Byrtek M. Oral Health of Irish Adults 2000-2002. 2007; Department of Health, Dublin.

7. Casanova L, Hughes F. J. Preshaw P. M. Diabetes and periodontal disease: a two-way relationship. British Dental Journal. 2014; 217: 433-437.

8. Leira Y, Seoane J, Blanco M, Rodriguez-Yanez M, Takkouche B, Blanco J, Castillo J. Association between periodontitis and ischemic stroke: a systematic review and metaanalysis. Eur J Epidemiol. 2017; 32(1):43-53.

9. Hung HC, Joshipura KJ, Colditz G, Manson JE, Rimm EB, Speizer FE, Willett WC. The Association between Tooth Loss and Coronary Heart Disease in Men and Women. $J$ Public Health Dentistry. 2004; 64(4):209-15. 
10. Petersen PE, Bourgeois D, Ogawa H, Estupinan-Day S, Ndiaye C. The global burden of oral diseases and risks to oral health. Bulletin of the World Health Organisation. 2005; 83(9):661-9.

11. Peterson PE, Kandlema D, Arpin S and Ogawa H. Global Oral Health of Older People - Call for public health action. Community Dental Health. 2010; 27, (Supplement 2): 257-268.

12. O'Sullivan V and O'Connell BC. Water fluoridation, dentition status and bone health of older people in Ireland. Community Dent Oral Epidemiol. 2015; 43(1):58-67.

13. Lamster I, Lalla E, Wench S, Borgnakke DDS, Taylor G. The Relationship Between Oral Health and Diabetes Mellitus. The Journal of the American Dental Association. 2008; 139:(Suppl 5):19-24

14. Steele $\mathrm{J}$ and Hackett $\mathrm{E}$. A vision for improved oral health in Ireland. Outcome from the First National Oral Health Forum, November 2013. Retrieved from http://www. dentalhospital.ie/a-vision-for-improved-oral-health-ireland/

15. Singh M and Papas A. Oral Implications of Polypharmacy in the Elderly. Dental Clinics of North America. 2014: 58;4: 783-796.

16. Ward M, McGarrigle C. The Contribution of Older Adults to their Families and Comminity. In McGarrigle C, Donoghue O, Scarlett S \& Kenny RA (eds.), Health and wellbeing: active ageing for older adults in Ireland. Evidence from The Irish Longitudinal Study on Ageing. 2017; Dublin: The Irish Longitudinal Study on Ageing.

17. Department of the Taoiseach. 2016. A Programme for a Partnership Government. Pp55-56. http://www.taoiseach.gov.ie/eng/Work_Of_The_Department/Programme_for_ Government/A_Programme_for_a_Partnership_Government.pdf. Retrieved June 2016.

18. Department of Health. National Oral Health Policy. 2014. http://health.gov.ie/futurehealth/reforming-primary-care-2/national-oral-health-policy/. Retrieved June 2017.

19. Kennedy, C. National Oral Health Policy. Stakeholders Consultation Day. Summary Report. Department of Health. Dublin. 2015. Available at http://health.gov.ie/wpcontent/uploads/2015/10/Stakeholders-Consultation-Day_Summary-Report_FINAL.pdf. Retrieved June 2017 


\section{Appendix}

The most comprehensive is the Dental Treatment Services Scheme for adult medical cardholders. Medical card entitlement is based primarily on income, with higher thresholds for those aged over 70. Adult medical cardholders are entitled to attend Health Services Executive (HSE)-contracted private dentists for a free dental examination, two fillings, denture repairs, and one root canal treatment in each calendar year plus any extractions. Denture repairs can also be carried out at HSE-contracted dental technicians. For most other treatments including dentures and periodontal/gum treatment, prior approval must be sought from the HSE, with priority given to those with special needs/high risk, including clients who are pregnant, have diabetes, are immuno-compromised or need certain surgical procedures.

Workers who pay social insurance (PRSI) are entitled to a free check-up each year at private dental practices contracted to the Department of Social Protection, but must pay for any additional treatments, although there are plans to reintroduce free teeth cleaning. Primary schoolchildren receive free dental check-ups and certain treatments in HSE clinics at specified intervals. Private dental practices must follow a Dental Council code of conduct by displaying information on treatment fees in their practices and patients can claim tax relief on certain specialist (but not routine) treatments. A few private health insurance policies also provide dental cover. Irish public water supplies which provide water to $84 \%$ of homes have been fluoridated since the 1960 s as a public health measure to reduce dental caries (12). 




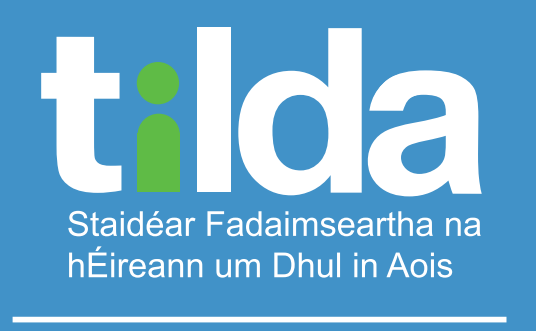

The Irish Longitudinal Study on Ageing 